\title{
Long-term treatment with bisphosphonates and their safety in postmenopausal osteoporosis
}

This article was published in the following Dove Press journal:

Therapeutics and Clinical Risk Management

16 July 2010

Number of times this article has been viewed

\author{
Michael Pazianas' \\ Cyrus Cooper ${ }^{1,2}$ \\ F Hal Ebetino ${ }^{3}$ \\ R Graham G Russell 1,4 \\ 'The Botnar Research Centre and \\ Oxford University Institute of \\ Musculoskeletal Sciences, Nuffield \\ Department of Orthopaedics, \\ Rheumatology and Musculoskeletal \\ Diseases, Nuffield Orthopaedic \\ Centre, Headington, Oxford, UK; \\ 2MRC Epidemiology Resource \\ Centre, University of Southampton, \\ Southampton General Hospital, \\ Southampton, UK; ${ }^{3}$ Warner \\ Chilcott, New Jersey, USA; ${ }^{4}$ The \\ Mellanby Centre for Bone Research, \\ Department of Human Metabolism, \\ Sheffield University Medical School, \\ Sheffield, UK
}

\begin{abstract}
Bisphosphonates are the leading drugs for the treatment of osteoporosis. In randomized controlled trials (RCTs), alendronate, risedronate, and zoledronate have shown to reduce the risk of vertebral, nonvertebral, and hip fractures, whereas RCTs with ibandronate show antifracture efficacy at vertebral sites. Bisphosphonates are generally well tolerated and safe. Nevertheless, adverse events have been noted, and it is important to consider the strength of the evidence for causal relationships. Effects on the gastrointestinal tract and kidney function are well recognized, as are transient acute-phase reactions. Atrial fibrillation was first identified as a potential adverse event in a zoledronate trial, but subsequent trials and analyses failed to substantiate an association with bisphosphonates. Case reports have suggested a relationship between oral bisphosphonates and esophageal cancer, but this has not been demonstrated in epidemiologic studies. A possible association between bisphosphonate use and osteonecrosis of the jaw (ONJ) has also been suggested. However, the risk of ONJ in patients with osteoporosis appears to be very low, with no evidence from prospective RCTs of a causal association. There are reports of occasional occurrence of subtrochanteric or diaphyseal fractures in osteoporotic patients, but an association with bisphosphonate therapy is not substantiated by epidemiologic studies or prospective RCTs.
\end{abstract}

Keywords: bisphosphonates, osteoporosis, safety

\section{Introduction}

Osteoporosis is a common disease characterized by low bone mass and structural deterioration of bone tissue, resulting in decreased bone strength and increased susceptibility to fractures. ${ }^{1}$ At menopause, estrogen production declines, leading to unbalanced bone remodeling. Bone resorption occurs at a higher rate than bone formation and, as a result, bone is progressively lost, leading to postmenopausal osteoporosis and an increased risk of fragility fractures. ${ }^{2}$ Vertebral fractures can lead to chronic pain and deformity with advanced disease. Both hip and spine fractures are associated with increased mortality, and a substantial economic burden. ${ }^{3-5}$ Therapeutic interventions that mitigate fracture risk are, therefore, essential for reducing the consequences of this debilitating condition.

Nitrogen-containing bisphosphonates, such as alendronate, risedronate, ibandronate, and zoledronate (also known as zoledronic acid ${ }^{a}$ ), are agents that inhibit bone resorption, and are currently used as first-line treatment for osteoporosis. ${ }^{6,7}$ Their

${ }^{a}$ All bisphosphonates exist as salts rather than acids at physiological $\mathrm{pH}$, so it is not technically accurate for zoledronate to be called zoledronic acid. To be consistent with the nomenclature for other bisphosphonates, we have used the term zoledronate throughout this text. submit your manuscript | www.dovepress.com

Dovepress

8054
Therapeutics and Clinical Risk Management 2010:6 325-343

(C) 2010 Pazianas et al, publisher and licensee Dove Medical Press Ltd. This is an Open Access article which permits unrestricted noncommercial use, provided the original work is properly cited. 
antiresorptive action results from both their affinity for bone mineral and their inhibitory effect on osteoclast cell function. Significant differences in binding affinity to bone mineral have been found among the bisphosphonates in vitro, with a rank order of highest to lowest as follows: zoledronate $>$ alendronate $>$ ibandronate $>$ risedronate. ${ }^{8,9}$ Similarly, the degree to which bisphosphonates reduce osteoclastic activity by inhibition of farnesyl pyrophosphate synthase also differs among them, with a rank of order from highest to lowest as follows: zoledronate $>$ risedronate $>$ ibandronate $>$ alendronate. ${ }^{10,11}$ These differences are explained principally by the three-dimensional configuration of each bisphosphonate and, as a result, each bisphosphonate offers a unique combination of pharmacologic properties. ${ }^{7}$ As a class, bisphosphonates increase the bone mineral density (BMD), decrease the levels of biomarkers of bone resorption, and reduce the risk of osteoporotic fractures. In 2004, 55 million prescriptions for bisphosphonates were written in the United States alone. ${ }^{12}$ Clinically, the bisphosphonates are considered to be a very safe drug class, given their specific bone-targeting capability. However, there are some safety concerns that are discussed in this article.

This article reviews the key clinical profiles of the bisphosphonates commonly used for the treatment of postmenopausal osteoporosis in terms of their efficacy in the reduction of fracture risk at vertebral and nonvertebral sites. It also reviews their safety profiles, including effects on the gastrointestinal tract (GI), musculoskeletal tolerability, renal safety, atrial fibrillation (AF), osteonecrosis of the jaw (ONJ), subtrochanteric or diaphyseal fractures, and possible adverse effects on bone turnover. In preparing this review, we have made a comprehensive search using PubMed with subject headings for the individual bisphosphonates. This covers the period up to December 2009. There have been other recent reviews covering some of these topics. ${ }^{13,14}$

\section{Efficacy \\ Efficacy over the first 3 years of treatment}

Four nitrogen-containing bisphosphonates have been approved in both the United States and in Europe: alendronate, risedronate, ibandronate, and zoledronate. All these four bisphosphonates have met US Food and Drug Administration (FDA) and European requirements for the treatment of osteoporosis by significantly decreasing morphometric vertebral fractures over a 3-year treatment period. The approved nondaily oral regimens of weekly alendronate, weekly and monthly risedronate, and monthly ibandronate have not been evaluated in fracture-end point trials. Instead, it has been shown in bridging trials, based on BMD and bone biomarkers, that higher doses of these bisphosphonates coupled with longer intervals between doses result in equivalent results compared with their respective daily regimens.

Other bisphosphonates also have been used in osteoporosis but have not achieved broad indications and license. These include clodronate, pamidronate, tiludronate, neridronate, minodronate, and olpadronate. Etidronate was approved in most countries in the early 1990s. Pamidronate has been extensively used off-label for osteoporosis as it was the only intravenous (IV) bisphosphonate available. A further discussion of these compounds is beyond the scope of this review.

In prospective double-blind randomized placebocontrolled trials (RCTs), alendronate, risedronate, and zoledronate have been shown to reduce the risk of both vertebral and nonvertebral fractures, including those of the hip. ${ }^{15-21}$ Prospective studies with ibandronate have also shown antifracture efficacy at vertebral sites but did not show a significant reduction in nonvertebral or hip fracture risk in the overall study population of the phase III fracture trial. ${ }^{22}$

\section{Alendronate}

Alendronate was the first oral nitrogen-containing bisphosphonate to be licensed for osteoporosis, initially in the United States, in 1995. The Alendronate Phase III Osteoporosis Treatment Study $^{23}$ demonstrated a $48 \%$ overall reduction $(P=0.03)$ in the risk of radiographically defined vertebral fractures in women with low BMD. In the Fracture Intervention Trial (FIT) that followed, 3 years of alendronate treatment $(5 \mathrm{mg} /$ day for 2 years followed by $10 \mathrm{mg} /$ day for the last year) in women with previous vertebral fractures was shown to reduce the risk of vertebral and hip fractures by $47 \%(P<0.001)$ and $51 \%(P=0.047)$, respectively. ${ }^{15}$ In women with osteoporosis but no vertebral fracture, 4 years of alendronate treatment $(5 \mathrm{mg}$ /day for 2 years followed by $10 \mathrm{mg} /$ day for the remainder of the trial) was associated with a $44 \%(P=0.002)$ reduction in the risk of vertebral fracture. ${ }^{16}$ Post hoc analyses of the pooled populations showed that alendronate treatment significantly reduced the risk of clinical vertebral fracture after 12 months of treatment (59\%; $P<0.001)$, whereas hip and nonvertebral fracture risk were significantly reduced by month 18 and $24(63 \% ; P=0.014$ and $26 \% ; P=0.011$, respectively). ${ }^{24}$ The placebo-controlled Fosamax International Trial demonstrated that 1 year of treatment with alendronate $(10 \mathrm{mg} /$ day $)$ reduced the risk of nonvertebral fractures by $47 \%(P=0.021)$ in postmenopausal women with low BMD. ${ }^{17}$ In active-control studies, 
twice-weekly (35 $\mathrm{mg}$ ) and weekly (70 $\mathrm{mg}$ ) dosing regimens of alendronate showed comparable efficacy to $10 \mathrm{mg}$ daily dosing, based on changes from baseline in lumbar spine BMD. ${ }^{25,26}$

\section{Risedronate}

In the North American arm of the Vertebral Efficacy with Risedronate Therapy (VERT) trial, 3 years of treatment with risedronate $(5 \mathrm{mg} /$ day) in women with at least one vertebral fracture reduced the risk of a new vertebral fracture by $41 \%$ $(P=0.003)$, and was also associated with a $39 \%$ reduction in the risk of nonvertebral fracture $(P=0.02) .{ }^{18}$ In the multinational arm of the VERT trial, treatment with risedronate ( $5 \mathrm{mg}$ /day) over 3 years significantly decreased the risk of new vertebral fractures by $49 \%(P<0.001)$ in women starting with at least two prevalent vertebral fractures. The risk of nonvertebral fractures was reduced by $33 \%$, a nonsignificant difference compared with placebo $(P=0.06) .{ }^{19}$ In elderly women (70-79 years of age) with osteoporosis (T-score -4 or less, or T-score -3 or less and a nonskeletal risk factor for hip fracture), 3 years of treatment with risedronate was found to reduce the incidence of hip fracture by $40 \%$ compared with placebo $(P=0.009) .{ }^{20}$ Post hoc analyses from placebo-controlled trials enrolling postmenopausal women with osteoporosis (determined on the basis of prevalent vertebral fractures, low $\mathrm{BMD}$, or both) have indicated that risedronate ( $5 \mathrm{mg} /$ day) significantly reduces the clinical vertebral and nonvertebral (66\%; $P=0.048$ ) fracture incidence as early as 6 months after beginning treatment. ${ }^{27,28}$ In active-control studies, weekly (35 mg) and monthly (75 $\mathrm{mg}$ on two consecutive days per month [2CDM] or $150 \mathrm{mg}$ once a month [OaM]) dosing regimens were found to be noninferior to daily ( $5 \mathrm{mg}$ ) dosing, based on mean increases from baseline in lumbar spine BMD. ${ }^{29-31}$ The studies with risedronate $75 \mathrm{mg}$ 2CDM and $150 \mathrm{mg}$ OaM also included new incident vertebral fractures as a second efficacy measure at 12 months. New vertebral fractures occurred infrequently and, in each of the two studies, the incidence of new vertebral fractures was similar between the monthly and the daily treatment groups. ${ }^{30,31}$ When examining different dosing regimens, some studies have compared the results of matched historical control data from previous placebo-controlled trials, as an alternative option when placebo controls are not practical or ethical. Thus, active-control studies with risedronate dosed at $35 \mathrm{mg}$ weekly, ${ }^{32} 75 \mathrm{mg} 2 \mathrm{CDM},{ }^{33}$ or $150 \mathrm{mg} \mathrm{OaM}^{34}$ showed similar efficacy, as measured by BMD, to risedronate $5 \mathrm{mg}$ daily over a period of 1 year, as well as a reduction in vertebral fracture risk of 77,79 , and $72 \%$, respectively, compared with a historical placebo-control group.

\section{Ibandronate}

The oral iBandronate Osteoporosis vertebral fracture trial in North America and Europe (BONE) demonstrated that 3 years of oral treatment with ibandronate $(2.5 \mathrm{mg} /$ day $)$ reduced the risk of vertebral fractures by $62 \%(P=0.0001)$ in postmenopausal women with a BMD T-score -2.0 or less and 1-4 prevalent vertebral fractures. ${ }^{22}$ Although the evaluation of the overall population did not indicate a significant reduction in the incidence of nonvertebral fractures, including those of the hip, a post hoc analysis of a higherrisk subgroup (femoral neck BMD T-score -3.0 or less) showed a reduction of $69 \%$ in nonvertebral fracture risk $(P=0.012)$, but the significance of this has been questioned since the group with a T-score $>-3.0$ showed an increase in fracture incidence. ${ }^{7,22}$ The Monthly Oral Bandronate in Ladies (MOBILE) noninferiority trial compared the efficacy of monthly oral ibandronate regimens (50 mg 2CDM; or $100 \mathrm{mg}$ or $150 \mathrm{mg}$ OaM) with daily dosing $(2.5 \mathrm{mg})$ with ibandronate. ${ }^{35,36}$ The results indicated that all once-monthly regimens were at least as effective as daily treatment, whereas the $150 \mathrm{mg}$ OaM regimen was found to be superior to the daily dosing, based on increases from baseline in lumbar spine BMD. Ibandronate can also be administered as an IV injection with extended dose-free intervals. To identify the optimal IV dosing regimen for postmenopausal women with osteoporosis, the Dosing IntraVenous Administration (DIVA) study compared the efficacy of 2-monthly ( $2 \mathrm{mg}$ ) ibandronate injection or 3-monthly (3 mg) ibandronate injection with the previously evaluated daily $2.5 \mathrm{mg}$ oral formulation. ${ }^{37,38}$ Based on mean increases in lumbar spine BMD, the results indicated that both IV regimens not only were noninferior but also produced larger increases than the oral daily dosing. In a further analysis of the data collated from different studies on ibandronate, using estimates of annual cumulative exposure, it has been suggested that there might be effects on nonvertebral fractures at higher doses. ${ }^{39,40}$

\section{Zoledronate}

Zoledronate is the only bisphosphonate developed solely for use as an IV formulation, and is now routinely prescribed when IV therapy is indicated. The Health Outcomes and Reduced Incidence with Zoledronic acid ONce yearly (HORIZON) Pivotal Fracture Trial demonstrated the efficacy of a single yearly infusion of 5-mg zoledronate in postmenopausal women with a BMD T-score -2.5 or less, or a BMD T-score -1.5 or less and prevalent vertebral fracture(s). ${ }^{21}$ Over a 3-year treatment period, the risk of vertebral, nonvertebral, and hip fractures was reduced by $70 \%$ ( $P<0.001$ ), $25 \%$ 
$(P<0.01)$, and $41 \%(P=0.002)$, respectively. Reductions in vertebral fracture risk were observed as early as 12 months after initiation of treatment $(60 \% ; P<0.001)$. Reductions in hip and nonvertebral fracture risk were observed at 24 months. The HORIZON Recurrent Fracture Trial assessed the antifracture efficacy of zoledronate in patients (women and men) with a recent hip fracture. ${ }^{41}$ In this population, the rates of clinical vertebral and nonvertebral fracture were reduced by $46 \%(P=0.02)$ and $27 \%(P=0.03)$, respectively, after 2 years of treatment. Notably, a reduction of $28 \%(P=0.01)$ in deaths from any cause was observed in the treatment group compared with placebo patients. ${ }^{42}$ This is an intriguing finding that merits further study, especially since other treatments for osteoporosis may also favorably affect mortality. ${ }^{43}$

\section{Head-to-head trials}

There are unfortunately very few direct comparisons of efficacy between bisphosphonates in clinical trials, and those available used surrogate end points such as BMD and markers of bone turnover rather than fractures. The Fosamax-Actonel Comparison Trial (FACT) was a 2-year head-to-head study comparing clinical outcomes between once-weekly alendronate $70 \mathrm{mg}$ and once-weekly risedronate $35 \mathrm{mg}$. The results revealed greater gains in BMD and greater reductions in markers of bone turnover with alendronate compared with risedronate. ${ }^{44,45}$ In the noninferiority head-to-head 1-year MOTION study, once-monthly ibandronate $150 \mathrm{mg}$ was found to be clinically comparable to once-weekly alendronate $70 \mathrm{mg}$ with regard to increasing BMD and decreasing bone turnover markers from baseline. ${ }^{46,47}$ Nevertheless, it should be noted that although an increase in $\mathrm{BMD}$ can reflect lower fracture risk, larger increases in BMD do not necessarily result in greater reductions in vertebral or nonvertebral fracture risk..$^{48}$ In fact, several studies have shown that increases in BMD are not directly proportional to decreases in fracture risk. ${ }^{48,49}$ Similarly, a reduction of bone resorption and turnover markers below a certain threshold may not lead to a further reduction of vertebral or nonvertebral fracture risk. ${ }^{50}$

\section{Long-term efficacy (more than 3 years of treatment)}

The clinical outcomes of treatment with alendronate, risedronate, or zoledronate have been evaluated in the postmenopausal setting for up to 10,7 , and 5 years, respectively. ${ }^{51-55}$ The outcomes of administering ibandronate formulations in postmenopausal osteoporosis have so far only been reported for up to 3 years of treatment.

\section{Alendronate}

To evaluate the long-term efficacy of alendronate, a follow-up long-term extension to the FIT trial was conducted. Patients assigned to alendronate therapy in the FIT trial were rerandomized for an additional 5 years to alendronate or placebo. ${ }^{51,52}$ Patients who were switched to placebo after 5 years of treatment with alendronate ( 5 or $10 \mathrm{mg}$ daily) had no increase in the risk of morphometric vertebral fractures or nonvertebral fractures over the next 5 years compared with patients who continued alendronate for up to 10 years. However, the risk of clinically diagnosed vertebral fractures was significantly lower (55\%) among those who continued therapy compared with those who discontinued alendronate after 5 years of treatment. ${ }^{52}$ In summary, Black et al concludes that continuous treatment with alendronate beyond 5 years and up to 10 years may not be necessary for all patients, since discontinuing alendronate after 5 years does not appear to significantly increase fracture risk. Women at high risk of fractures may, however, benefit by continuing therapy with alendronate beyond 5 years of treatment.

\section{Risedronate}

To evaluate the long-term antifracture efficacy of risedronate, the 3-year VERT multinational study was extended for an additional 2 years, during which patients continued double-blind treatment according to the original randomization. It was shown that the effects of risedronate on vertebral fracture risk over 3 years are maintained at the same magnitude with a further 2 years of treatment. ${ }^{53}$ During years $4-5$, vertebral fracture incidence was $59 \%$ lower with risedronate $(5 \mathrm{mg} /$ day $)$ than with placebo $(P=0.01)$, whereas a $49 \%$ reduction in vertebral fracture risk had been seen in the first 3 years of treatment. At the end of the 5-year study period, all patients were offered open-label risedronate therapy ( $5 \mathrm{mg} /$ day) for 2 additional years. In patients continuously treated with risedronate, the incidence of vertebral fractures during years $6-7$ (3.8\% per year) was similar to what was observed in years $4-5$ (5.2\% per year) and years $0-3$ (4.7\% per year). The incidence of nonvertebral fractures in years 6-7 was low and comparable to the incidence observed in the first 3 years. ${ }^{54}$ In summary, results indicated that patients treated for up to 7 years with risedronate do not experience a decrease in the degree of fracture protection.

In the North American arm of the VERT study, patients stopped therapy as per protocol after 3 years and were given the option of remaining in the study for the fourth year, during 
which active treatment and placebo were discontinued. In the year off treatment, the BMD of patients previously treated with risedronate decreased but remained higher than baseline BMD and the BMD of patients previously on placebo. The incidence of new vertebral fractures in the year after discontinuation of 3 years of treatment was $46 \%$ lower in the former risedronate group than in the former placebo group. ${ }^{56}$ This antifracture effect and increase in biomarkers may still be seen after stopping treatment after 7 years. ${ }^{57}$

\section{Zoledronate}

The antifracture efficacy of zoledronate in the osteoporosis setting has not yet been reported beyond 3 years of treatment for the $5 \mathrm{mg}$ once-yearly dosing regimen. ${ }^{21}$ However, a smaller group of patients receiving a cumulative dose of $2 \mathrm{mg}$ annually and a larger group receiving a 4-mg dose were evaluated in a 5-year study. The study included an initial 1-year, randomized, double-blind, placebo-controlled trial that was followed by 2 consecutive, open-label, 2-year extension studies. Treatment with zoledronate was associated with a sustained increase in BMD and reductions in bone turnover. The BMD gains achieved by month 36 were well maintained for a further 2 years in all patients. ${ }^{55} \mathrm{~A}$ bone turnover marker analysis during 2 years off treatment after 1 year of therapy has recently been reported and suggests that reduction of markers is comparable at 12 and 24 months. ${ }^{58}$

\section{Tolerability and safety}

To assess the tolerability and safety, it is important to take into account the way in which data are derived. Tolerability is best evaluated using prospective double-blind RCTs. Data regarding tolerability are derived in several ways from such studies, including recording the number of patients who withdraw from further participation, the reasons for these withdrawals such as adverse events, as well as the rate of discontinuation of study medication. It is also important to take into account the inclusion criteria used in the studies, as these may influence the reported rates of tolerability and adverse events. For example, the exclusion of patients with preexisting GI problems is likely to affect the rate at which GI events are recorded.

\section{General safety}

Bisphosphonates are one of the most thoroughly studied groups of drugs used in medicine. Since their first use in 1969, their efficacy and safety have been established through a series of comprehensive trials for their various clinical uses, in Paget's disease, in myeloma and bone metastases, as well as in osteoporosis. This includes the trials with nitrogen-containing bisphosphonates in which over 60,000 participants were followed for 3 years or longer. All 4 currently approved nitrogen-containing bisphosphonates have a favorable tolerability and safety profile as indicated by the dispensing of over 190 million oral bisphosphonate prescriptions worldwide by $2006 .{ }^{59}$ Their remarkable safety profile is partly explained by their strong affinity for bone mineral that prevents their uptake by most other tissues, even at pharmacologic concentrations. Their retention time in the skeleton is long but they are efficiently cleared from the systemic circulation, and peak levels are short-lasting. After administration, these peak levels are still submicromolar and transient, since bisphosphonates are rapidly cleared by skeletal uptake and by excretion through the kidneys. ${ }^{7}$ However, trace amounts can be detected in body fluids for very long periods after dosing. ${ }^{60,61}$

After treatment with alendronate (3-10 years), risedronate (3-5 years), or ibandronate ( 3 years), the incidence of overall adverse events, serious adverse events, drug-related adverse events, as well as withdrawal rates due to adverse events were similar between each treatment and its respective placebo arm. ${ }^{15-20,22,52,53}$ In an open-label follow-up study, the safety profile of risedronate was assessed during years 6-7 of treatment. No additional safety concerns were observed when compared with the first 3 or 5 years of treatment. ${ }^{54}$ In an active-control trial, the tolerability profile of IV ibandronate over 2 years of treatment was found to be similar to that observed with daily oral therapy. ${ }^{38}$ In the HORIZON studies with zoledronate, withdrawal rates due to adverse events were similar across treatment and placebo groups. ${ }^{21,41}$ However, in the HORIZON Pivotal Fracture Trial, the overall incidence of any adverse event was significantly higher in the zoledronate group compared with placebo (95.5\% vs $93.9 \%$; $P=0.002$ ), primarily due to a larger number of events due to acute-phase reactions. ${ }^{21}$

\section{Head-to-head trials}

There are very few studies that compare efficacy and safety of different bisphosphonates head to head. The FACT trial is one example in which the incidence of adverse events, serious adverse events, or adverse events leading to discontinuation was found to be similar when groups treated with alendronate or risedronate were directly compared. This trial included patients affected by upper GI side effects. ${ }^{44}$ In the MOTION trial, alendronate $35 \mathrm{mg}$ weekly and ibandronate 
$150 \mathrm{mg}$ monthly were compared. This trial also showed that the rates of adverse events, serious adverse events, adverse events leading to withdrawal, and upper GI tract adverse events, were similar across the alendronate and ibandronate treatment groups, but with the incidence of short-term events, such as influenza-like illness due to acute-phase reactions, being greater in the ibandronate treatment group. ${ }^{46,47}$

\section{Adverse effects attributed to bisphosphonates}

Adverse events attributed to bisphosphonates are identified from various sources which provide different levels of confidence that the effects are truly due to the drugs. Thus, events identified in RCTs should represent the best evidence for an association, since randomization should ensure that placebo and treatment groups are matched in other respects than the treatment they received. However, even in the case of RCTs, the large number of types of adverse events that are recorded means that occasionally significant differences $(<5 \%)$ will arise by chance alone. The occurrence of AF in the HORIZON trials with zoledronate could represent a possible example.

The weakest evidence for an association between a drug and an adverse event is derived from postmarketing spontaneously reported cases or case series where the incidence of such effects in the untreated population is unknown. Intermediate levels of association can be derived from many other sources, eg, investigator-driven trials, epidemiologic studies, and registry data. A further criterion that should be applied when assessing whether an adverse event is truly related to the drug or whether there is a plausible mechanism for the association. Thus, "well recognized" adverse events for which there is a plausible mechanistic basis include GI intolerance, effects on renal function, and the development of acute-phase reactions, particularly after the first IV administration. These adverse events can in most cases be avoided or managed effectively. A greater challenge, however, is how to properly assess adverse events where no clear causal association or explanation exists. Among these events are ONJ, AF, subtrochanteric or diaphyseal fractures, esophageal cancer, and ocular inflammation.

\section{Gastrointestinal safety}

GI problems are often considered to be an inevitable consequence associated with the oral use of bisphosphonates, which are currently extensively prescribed (alendronate, risedronate, and ibandronate) for the prevention and treatment of osteoporosis. However, the results from the major prospective RCTs assessing the reduction of fractures are notable in not showing an excess of GI problems. Oral bisphosphonates are in general poorly absorbed $(<1 \%)$ from the intestinal tract, which means that potentially large amounts of bisphosphonates can come into contact with the GI mucosa at all levels of the GI tract. Indeed diarrhea was recognized as a side effect of giving large amounts of the early bisphosphonates, etidronate and clodronate, and seems not to be an issue with the current clinically used bisphosphonates, which are given in smaller amounts.

It is generally acknowledged that upper GI symptoms are very common in elderly patients whether or not bisphosphonates are given. In contrast, the more severe side effects associated with esophageal events such as ulceration are rare but potentially more serious, and were noted in particular after giving oral pamidronate ${ }^{62}$ or alendronate. ${ }^{63}$ In terms of practical management, the interference of absorption by food as well as these esophageal problems are minimized in patients taking oral bisphosphonates on an empty stomach, first thing in the morning, with sufficient plain water, while remaining in an upright position without eating or further drinking for at least 30 minutes (60 minutes in the case of ibandronate). ${ }^{64-66}$ Strict adherence to these instructions is thought to reduce the incidence of serious esophageal adverse events. Optimal formulation also appears to have a role in reducing GI events.

In RCTs of bisphosphonates, upper GI complaints have been reported at similar frequencies in placebo and activetreatment groups. However, postmarketing studies have indicated that oral bisphosphonates can be associated with GI tract intolerance. ${ }^{67}$ Studies showed that a significant proportion of patients are less compliant with administration instructions outside clinical supervision, and so are more likely to experience side effects. ${ }^{68}$

\section{Alendronate}

In the vertebral fracture arm of the FIT trial, ${ }^{15}$ upper GI tract adverse events affected $41.3 \%$ and $40.0 \%$ of patients in the alendronate and placebo group, respectively. In the clinical fracture arm, these events affected $47.5 \%$ of patients in the alendronate group vs $47.2 \%$ of placebo patients. ${ }^{16}$ Three years into the long-term extension trial of alendronate, $35.7 \%$ of patients taking placebo reported upper GI tract adverse events compared with $29.8 \%$ of patients taking alendronate $(P=0.041) .{ }^{51}$ Patients with prior GI problems were excluded from these studies in contrast to the risedronate trials. 
To determine whether there was a relationship between the dose of alendronate and the incidence of these events, an analysis of data from the 2 arms of the FIT study compared reports during the first 2 years of the trial (when patients received $5 \mathrm{mg}$ alendronate or placebo) with reports during years 3 through 4.5 (when patients received 10-mg alendronate or placebo). The proportion of patients affected by upper GI events was similar in the alendronate and placebo groups during treatment with $5 \mathrm{mg}$ or $10 \mathrm{mg}$ daily dosing. The study further demonstrated that alendronate use was not associated with a significant increase in upper GI tract events among patients at increased risk of those events (age 75 years or older, with previous upper GI disease, or using nonsteroidal anti-inflammatory drugs [NSAIDs]). ${ }^{69}$

However, rare but serious upper GI events were recognized as a problem soon after alendronate was launched as a daily oral medication. In 1996, de Groen et a ${ }^{63}$ published a summary of the postmarketing adverse event reports on alendronate received by Merck up to 5 March 1996. There were 199 reported cases of upper GI side effects of which 51 were classified as being serious or severe out of an estimated 475,000 patients to whom the drug had been prescribed for the treatment of osteoporosis or Paget disease, ie, an incidence rate of about $0.01 \% .^{63}$

\section{Risedronate}

Upper GI complaints were the most common adverse events reported in the VERT multinational 3-year study, affecting $27 \%$ and $26 \%$ of patients in the risedronate and placebo groups, respectively. ${ }^{19}$ During the 2-year extension study, the incidence of these events was lower at $12.6 \%$ in the risedronate group and $13.8 \%$ in the placebo group. ${ }^{53}$ The incidence of GI adverse events reported during years 6-7 was even lower at $9.6 \%$ in patients continuously treated with risedronate for 7 years and $8.6 \%$ in patients receiving placebo for the first 5 years and risedronate in the last two study years. ${ }^{54}$ To investigate further the upper GI tract safety of risedronate ( $5 \mathrm{mg} /$ day), data from 9 placebo-controlled, phase III clinical trials were pooled to increase statistical power and allow the detection of differences between treatment and placebo groups. ${ }^{70}$ This analysis included 10,068 men and women, representing approximately 10,500 patientyears of exposure to risedronate. The results confirmed that upper GI tract adverse events were similarly distributed across the placebo (29.6\% of patients) and risedronate $(29.8 \%$ of patients) groups. Concomitant use of aspirin and/or NSAIDs did not result in a higher frequency of upper GI tract adverse events in the risedronate group compared with the placebo group. The use of $\mathrm{H}_{2}$-receptor antagonists and/or proton pump inhibitors also did not lead to significant differences in the incidence of these events between risedronate and placebo groups. Patients with active GI disease receiving risedronate did not experience worsening of their underlying condition or an increase in frequency of GI side effects. ${ }^{70}$

\section{Ibandronate}

The BONE trial showed comparable rates of upper GI tract adverse events in ibandronate and placebo groups, over 3 years of treatment. ${ }^{22}$ Subgroup analysis of patients with and without a history of GI disorders indicated that ibandronate did not increase the overall risk of upper GI adverse events compared with placebo in patients with such a history. In addition, among those who used aspirin or NSAIDs, the incidence of these events was similar in patients treated with ibandronate or placebo. ${ }^{22}$ The DIVA study revealed lower incidences of upper GI disorders in patients treated with 3-mg ibandronate IV 3 monthly than in patients receiving oral therapy $2.5 \mathrm{mg}^{71}$

\section{Zoledronate}

In the HORIZON Pivotal Fracture Trial, nausea $(8.5 \%$ vs $5.2 \%$ ), vomiting ( $4.6 \%$ vs $3.2 \%)$, diarrhea $(6.0 \%$ vs $5.6 \%)$, upper abdominal pain (4.6\% vs $3.1 \%)$, and dyspepsia $(4.3 \%$ vs $4.0 \%$ ) were reported more frequently in patients treated with zoledronate than in placebo patients. ${ }^{72}$ In the HORIZON Recurrent Fracture Trial, only diarrhea occurred numerically more often in patients treated with zoledronate $(5.2 \%)$ as compared with placebo $(4.7 \%){ }^{72}$

\section{Generic bisphosphonates and gastrointestinal safety}

We are now in an era in which the patents on bisphosphonates are expiring and individual drugs are becoming available as generic formulations. For the treatment of osteoporosis, generic alendronate tablets are currently available in the United States, Canada, and Europe. Studies with preclinical models have suggested that esophageal irritation was greater in animals exposed to generic alendronate than in those exposed to branded alendronate. ${ }^{73}$ Differences in the disintegration profiles between the branded and the many different generic products available may result in GI problems. In fact, several studies have demonstrated differences in the in vitro disintegration properties between generic and branded alendronate products. ${ }^{7-76}$ Slower disintegration 
can lead to reduced efficacy, since bisphosphonates must be taken in the fasting state and contact with food or beverages markedly reduces bioavailability. Faster disintegration would increase the risk of esophagitis due to prolonged contact of the esophagus with bisphosphonates. ${ }^{74}$ Several generic alendronate products have been reported to have very rapid mean disintegration times, similar to those of commercially available orally disintegrating tablets (nonbisphosphonates). ${ }^{75,76}$ Although further investigation is needed, one should be aware that rapid disintegration may result in drug exposure in the mouth and/or esophagus during swallowing with potential adverse effects. There are reports ${ }^{77}$ that describe the clinical performance of patients switched to generic alendronate, where reductions in efficacy were noted, ${ }^{78}$ that may be linked to lowered overall performance of the generics.

\section{Renal safety}

Bisphosphonates are excreted unaltered through the kidneys via filtration and possibly by proximal tubular secretion. IV administration produces exposure to high initial concentrations of bisphosphonates in the kidney and may be associated with acute renal injury. This has not been shown for oral bisphosphonates when used as labeled, for the treatment of osteoporosis.

The administration of bisphosphonates is contra-indicated for use in patients with severe renal impairment (creatinine clearance $<30 \mathrm{~mL} / \mathrm{min}$ ) due to "lack of sufficient clinical experience" meaning that patients with at least stage 4 renal insufficiency were excluded from these studies. ${ }^{64-66,71,72}$ Recent publications indicate that the use of oral bisphosphonates (alendronate and risedronate) may be safe and effective in patients with glomerular filtration rates less than $30 \mathrm{~mL} / \mathrm{min} .{ }^{79-81}$ However, in clinical practice, one should still avoid administering bisphosphonates to patients with severe renal impairment because of the possible presence of adynamic bone disease, where any further reduction of bone turnover could be detrimental.

\section{Alendronate}

The efficacy and safety profile of alendronate $(5 \mathrm{mg}$ and $10 \mathrm{mg}$ daily) in patients with reduced renal function were evaluated in a post hoc analysis of data from the FIT trial. ${ }^{81}$ Compared with placebo, alendronate was equally effective in decreasing vertebral and nonvertebral fractures in patients with and without reduced renal function. No differences were observed in the frequency of adverse events in general, or renal adverse events in particular, in alendronate-treated patients with or without reduced renal function, indicating that data from the alendronate trials have not revealed obvious detrimental effects on renal function.

\section{Risedronate}

The efficacy and safety of risedronate in patients with renal impairment were evaluated in a 3-year retrospective study that used data from 9 risedronate trials. ${ }^{79}$ The incidence of vertebral fractures was significantly lower in the risedronate-treated patients than in the placebo group, for all subgroups of renal impairment (mild, moderate, and severe), indicating that patients with renal impairment may also benefit from a reduction in fractures. Vertebral fracture incidence in patients treated with risedronate was similar across renal impairment subgroups, whereas in patients receiving placebo the fracture incidence increased with the degree of renal impairment. The frequencies of adverse events and renal function-related adverse events were similar in the placebo and risedronate $(5 \mathrm{mg} /$ day $)$ groups, regardless of renal function. A more recent retrospective analysis evaluated the influence of the many dosing regimens ( 5 and $15 \mathrm{mg}$ daily, 35 and $50 \mathrm{mg}$ weekly, $75 \mathrm{mg} 2 \mathrm{CDM}$, and $150 \mathrm{mg} \mathrm{OaM}$ ) of risedronate on the renal function of patients with and without baseline renal function impairment or renal risk factors. ${ }^{80}$ The frequency distributions of changes in serum creatinine clearance from baseline to end point were not different between placebo and risedronate groups, nor between different dosing regimens of risedronate for each of the populations examined. Patients with baseline renal impairment or baseline renal risk factors also did not show treatment-group differences, indicating that risedronate had no obvious effect on these renal function parameters across a wide range of doses, regimens, and patient populations. ${ }^{80}$

\section{Ibandronate}

The renal tolerability and safety of IV ibandronate were compared with that of the daily oral regimen in the DIVA trial. The incidence of renal adverse events in the $3 \mathrm{mg}$ 3-monthly ibandronate group was low and similar to that observed in the $2.5 \mathrm{mg}$ daily group. Serum creatinine levels were also similar in both treatment groups at each time point and no cases of acute renal failure were reported. ${ }^{37}$

\section{Zoledronate}

In the HORIZON trial, the incidence of renal adverse events over 3 years was similar in the groups given zoledronate or placebo. ${ }^{21,41,72}$ Small and transient increases in serum creatinine levels were observed when patients were tested 
9 or 11 days after the infusion, but at 3 years there was no systemic deterioration in estimated creatinine clearance. However, treatment with zoledronate for conditions other than osteoporosis, such as metastatic bone disease and hypercalcemia of malignancy, has been associated with renal impairment and, in rare cases, acute renal failure. ${ }^{72}$ Longer infusion times are known to minimize renal effects of IV bisphosphonates. Severe nephrotoxicity can be largely avoided by adherence to guidelines for monitoring serum creatinine prior to each treatment, temporarily withholding therapy in the setting of renal insufficiency, and adjusting doses in patients with preexisting chronic kidney disease, ${ }^{82}$ and prolonging infusion times.

\section{Symptoms associated with an acute-phase reaction}

Symptoms consistent with short-term acute-phase reactions, including influenza-like illness and pyrexia, chills, myalgia, and arthralgia have been known to be associated with the administration of IV bisphosphonates since the use of pamidronate and other nitrogen-containing bisphosphonates from the 1970 s onwards. ${ }^{83,84}$ The acute-phase response is now a well-recognized feature with any of the nitrogen-containing bisphosphonates given IV at sufficient doses and can also occur after high oral doses. The underlying mechanisms have been studied in detail and appear to involve a rapid and profuse production of proinflammatory cytokines by peripheral blood gamma delta $(\gamma \delta) \mathrm{T}$ cells. This is mediated by the release of isopentenyl pyrophosphate (IPP) as a result of the blockade of the mevalonate pathway. ${ }^{85-88}$ IPP would subsequently activate/expand $\gamma \delta$ $\mathrm{T}$ cells by acting on a receptor that recognizes phosphate compounds.

In the case of IV zoledronate in the HORIZON trial, the proportion of patients who had any of the 5 most common acute-phase reaction symptoms (influenza-like illness, pyrexia, myalgia, headache, and arthralgia) within 3 days after the first infusion was significantly higher in the zoledronate group (31.6\%) than in the placebo group (6.2\%). The proportion of patients affected after subsequent infusions decreased substantially, ${ }^{21}$ although in some patients the symptoms associated with an acute-phase reaction occurred after subsequent doses. In the HORIZON trial to study the effect of zoledronate in preventing subsequent fracture after a hip fracture, these transient acute-phase reactions occurred less commonly, probably due to the routine administration of acetaminophen, although there was still a higher incidence in the zoledronate group $(6.8 \%$ vs $0.7 \%){ }^{41}$
In the case of ibandronate, in the DIVA study, the incidence of influenza-like illness, myalgia, and arthralgia, reported within 3 days of dosing and with a duration of less than 7 days, although generally low, was higher in patients receiving IV 3-monthly ibandronate (3.6, 1.3, and 1.3\%, respectively) than in patients receiving oral formulations $\left(0.6,0.2\right.$, and $0.2 \%$, respectively). ${ }^{37}$ The MOBILE study also revealed a higher proportion of patients diagnosed with influenza-like illness in the group given $150 \mathrm{mg}$ OaM oral ibandronate $(3.3 \%)$ than the $2.5 \mathrm{mg}$ daily comparator $(0.3 \%)$. These events were of short duration (1-4 days) and were associated with the first-administered dose. ${ }^{36}$

In the case of risedronate, based on reporting any of 33 acute-phase reaction-like symptoms within 5 days of the first dose, active-comparator studies with risedronate $75 \mathrm{mg}$ 2CDM showed an incidence of acute-phase reactions in $7.6 \%$ of patients compared with $3.6 \%$ in patients receiving risedronate $5 \mathrm{mg}$ daily. For the $150 \mathrm{mg}$ OaM oral regimen of risedronate, the overall incidence of acute-phase reactions (based on reporting any of 33 symptoms within 3 days of the first dose) was $5.2 \%$ compared with $1.1 \%$ in the $5 \mathrm{mg}$ daily group. ${ }^{65}$ These symptoms lasted for up to 7 days.

\section{Bone, joint, or muscle pain}

In postmarketing experience, there are infrequent case reports describing severe and occasionally incapacitating bone, joint, and/or muscle pain in patients taking bisphosphonates. The pain could occur days, months, or even years after starting bisphosphonates. It is probably different or, at least, not only associated with the acute-phase response and presents within the first few days after the first treatment with an IV bisphosphonate. Most patients reported relief of symptoms after discontinuing therapy and a subset had recurrence of pain when restarting treatment with the same or a different bisphosphonate. ${ }^{64-66,71,72,89}$ In spite of these case reports, there is minimal evidence from RCTs that these symptoms are linked to bisphosphonate therapy nor is there any obvious underlying mechanism. In placebo-controlled trials of alendronate (FIT), risedronate (VERT), and ibandronate (BONE), the incidence of these symptoms was similar in the treatment and placebo groups. ${ }^{64-66}$ However, in the HORIZON trials, bone and musculoskeletal pain were reported more frequently in the zoledronate group than in the placebo group. ${ }^{21,41,72}$

\section{Atrial fibrillation}

AF came to attention as a possible side effect of bisphosphonate therapy in the HORIZON Pivotal Fracture Trial in which there was a higher risk of serious AF in those participants 
taking zoledronate than in recipients of placebo. The vast majority of AF events were reported more than 30 days after infusion, by which time zoledronate would be at extremely low concentrations in the circulation. A total of 50 patients in the zoledronate group had serious AF (1.3\%), compared with 20 patients $(0.5 \%)$ in the placebo group $(P<0.001)$, whereas the incidence of any AF events was similar between treatment and placebo groups $(2.4 \%$ vs $1.9 \% ; P=0.12) .{ }^{21}$ In the Recurrent Fracture arm of the HORIZON trial, there was no evidence of this potential adverse event as the frequency of serious AF was similar in the zoledronate and placebo groups $(1.1 \%$ vs $1.3 \% ; P=0.84)$, as was the incidence of any $\mathrm{AF}$ event. ${ }^{41}$

The linkage of AF to bisphosphonates is even less clear with oral therapy. ${ }^{90}$ Cummings et $\mathrm{al}^{91}$ reported a trend towards an increased risk of serious but not all AF events in recipients of alendronate compared with placebo in the FIT trial. In the alendronate group, 47 patients $(1.5 \%)$ were reported to have serious AF vs 31 patients (1.0\%) in the placebo group $(P=0.07)$. Furthermore, an analysis of data from risedronate phase III clinical trials involving approximately 15,000 patients, receiving oral daily doses for up to 3 years, did not provide evidence of increased AF in general or serious AF. ${ }^{92}$ The incidence of any AF or serious AF events was $1.4 \%$ and $0.5 \%$, respectively, in the placebo group compared with $1.4 \%$ and $0.6 \%$, respectively, in patients treated with $5-\mathrm{mg}$ risedronate $(P=1.0$ and $P=0.49)$. There was also no difference in the rate of AF in patients treated with $150 \mathrm{mg}$ OaM of risedronate $(0.6 \%)$ vs $5 \mathrm{mg}$ daily $(0.5 \%)$. ${ }^{31}$ Recently, an analysis of pooled data from 4 pivotal ibandronate clinical trials showed no association with increased incidence of AF. $^{93}$

Case-control studies have been undertaken to assess the association between AF and bisphosphonate use. One of these studies analyzing data from the United States reported an increased risk of AF with the use of alendronate, ${ }^{94}$ whereas 2 reports from Denmark found no evidence that bisphosphonate use could increase such a risk. ${ }^{95,96}$

No evidence of an overall long-term increased risk of AF or flutter associated with continued exposure to alendronate or risedronate was found in a UK study assessing the risk of AF and flutter in women on an oral bisphosphonate. ${ }^{97}$ Most recently, a publication of the results from a meta-analysis stated that the heterogeneity of the existing evidence, as well as paucity of information on some of the agents, precludes any definitive conclusion on the exact nature of the risk. ${ }^{98}$
In October 2007, the FDA began reviewing placebocontrolled clinical trial information of alendronate, risedronate, ibandronate, and zoledronate to explore the potential risk of AF in patients treated with these agents. The review included data on 19,687 bisphosphonate-treated patients and 18,358 placebo-treated patients who were followed for 6 months to 3 years. In November 2008, the FDA issued a statement indicating that their review revealed no clear association between overall bisphosphonate exposure and the incidence of AF. It was also reported that increasing the dose or duration of therapy was not linked to an increased risk of AF. ${ }^{99}$ Similarly, a Europe-wide review, including clinical trial data, spontaneous reports of suspected adverse drug reactions, and published literature, concluded that the risk of AF in association with bisphosphonate treatment appears to be low, and the balance of risks and benefits for bisphosphonates remains favorable. ${ }^{100}$ Nevertheless, after the European Medicines Agency review, information on the incidence of AF was included in the Summary of Product Characteristics for zoledronate. ${ }^{101}$

\section{Ocular inflammation}

There have been occasional reports in the medical literature over many years indicating that bisphosphonates may be associated with ocular inflammation including conjunctivitis, iritis, episcleritis, scleritis, and uveitis. ${ }^{102,103}$ This was first recorded in spontaneous case reports with etidronate and other bisphosphonates. However, the trials with alendronate did not report this type of event ${ }^{64}$ and in active-control 2-year studies of risedronate, none of the patients treated with $75 \mathrm{mg}$ $2 \mathrm{CDM}$ or $150 \mathrm{mg}$ OaM reported ocular inflammation, whereas 3 patients treated with the active comparator (5-mg risedronate daily) developed an inflammatory reaction. ${ }^{65}$ In the trials with ibandronate, there were reports of ocular inflammation in patients treated with ibandronate $2.5 \mathrm{mg}$ daily, whereas 2 patients receiving $150 \mathrm{mg}$ OaM ibandronate experienced ocular reactions. ${ }^{66}$ In the HORIZON trials, the number of patients developing ocular inflammation was higher in patients treated with zoledronate when compared with placebo. ${ }^{21,41}$ Inflammation appeared within the first 15 days after the infusion. In addition, a few recent studies in cancer patients have reported ocular inflammation as a complication of zoledronate therapy, particularly after the first infusion. ${ }^{104-107}$ This complication can resolve after a short course of corticosteroid treatment. Prevention includes the avoidance of bisphosphonates or caution in their use (especially IV) for those with a history of inflammatory eye disease or uveitis. 


\section{Esophageal cancer}

Since the launch of the first oral amino-containing bisphosphonate, alendronate, in 1995 and up through May 2008, the FDA received reports of 23 cases of patients in the United States diagnosed with esophageal cancer, with alendronate as the suspect drug in 21 of them and the concomitant drug in the other 2 cases and this information was recently published. ${ }^{108}$ In the same publication, the characteristics of another group of 31 patients from Europe and Japan who had been treated with oral bisphosphonates (the vast majority on alendronate) were recorded. Risk factors were not described for all patients, but some were taking oral bisphosphonates despite absolute contraindications such as Barrett esophagus. Also, for some cases, the time from drug exposure to diagnosis was 6 months or less which makes the possibility of a causal relationship extremely unlikely. In an attempt to determine whether these rates of esophageal cancer are any different from the background rates in the population, Abrahamsen et a $1{ }^{96}$ used data from the Danish national registry. They individually matched 13,678 patients who suffered a fracture and filled more than 1 prescription for any oral bisphosphonate with 27,356 patients who suffered a fracture but were not treated with a bisphosphonate. The 2 groups were similar with respect to age, sex, and fracture type. Interestingly, the risk of esophageal cancer was significantly lower in those patients who were taking a bisphosphonate $(62 \%$ on alendronate, $36 \%$ on etidronate, and $2 \%$ on risedronate, ibandronate, or clodronate) when compared with the controls (hazard ratio $=0.35 \% ; 95 \%$ confidence interval $[\mathrm{CI}]$, $0.14-0.85 ; P=0.02)$. They also found that the risk of gastric cancer was not significantly different between the 2 groups (hazard ratio $=1.23 \% ; 95 \% \mathrm{CI}, 0.68-2.22 ; P=0.49$ ). The reporting of esophageal cancer as a possible complication of bisphosphonate therapy illustrates the pitfalls of case reports being used to support such claims when the background rates of the population are not taken into account. Moreover, there is no plausible mechanism by which such cancers are likely to be truly associated with bisphosphonate therapy.

In contrast, it has been suggested that bisphosphonates may be associated with a reduced rather than increased risk of certain cancers, eg, breast cancers. ${ }^{109}$ Such an association might be explained in part by low endogenous estrogen levels being associated both with breast cancer and with osteoporosis.

\section{Osteonecrosis of the jaw}

Since 2003, there have been a flurry of case reports and case series suggesting that bisphosphonate use may be associated with a condition called ONJ, which has many apparent similarities to osteomyelitis. Despite a substantial number of publications on the topic of bisphosphonates and ONJ, there are no prospective studies that demonstrate that bisphosphonate therapy contributes to the pathogenesis of this condition. Since the reported association is based on uncontrolled studies and the use of bisphosphonates has been used to define the condition (eg, bisphosphonate-related ONJ), it has been difficult to separate the background rates of ONJ-like pathologies such as osteomyelitis in the populations under study. ${ }^{110}$ Even though, in early reports, some authors suggested that oral bisphosphonates caused ONJ in patients with osteoporosis, more careful analysis of the relationship suggests that ONJ occurs only rarely in such patients whether treated with bisphosphonates or not. Indeed, recent systematic reviews of published and unpublished cases indicate that the use of bisphosphonates for osteoporosis is associated with an ONJ incidence of less than 1 in 100,000 patient-years of exposure, ${ }^{111,112}$ but the background rate of occurrence for comparison is unknown. The lack of reliable data and consistent definition of disease makes the incidence very difficult to determine. ${ }^{110,113}$

ONJ appears to occur most often in patients with advanced cancer, particularly in those with multiple myeloma or breast cancer, and specifically in those undergoing dental procedures. ${ }^{11,114}$ Many of these patients receive IV bisphosphonates as a necessary part of their treatment, but a direct and plausible causal association or pathophysiologic mechanism between bisphosphonates and ONJ has not been established.

The most reliable method for determining whether ONJ is associated with the use of bisphosphonates would be through prospective trials in which the incidence of ONJ in patients receiving bisphosphonates vs patients not receiving bisphosphonates would be compared and where all other health parameters are essentially equal. On this basis, all trials conducted to date show no evidence of association in osteoporosis or in cancer populations that also show no excess of ONJ cases in the bisphosphonate group compared with controls. In clinical trials of alendronate, risedronate, and ibandronate for osteoporosis indications, no cases of ONJ have been reported. In the HORIZON Pivotal Fracture Trial (an RCT involving approximately 8,000 patients), symptoms and signs consistent with ONJ developed in only 1 patient treated with zoledronate and 1 patient in the placebo group. Both cases resolved after appropriate treatment. ${ }^{21,72}$ 
The pathophysiology of ONJ is unclear and indeed infection is a common feature, suggesting that many of the lesions might be better defined as a form of osteomyelitis. ${ }^{115}$ The use of the term "osteonecrosis" may, therefore, be inappropriate. The current definition of ONJ is based on clinical findings and includes nonhealing lesions with exposed bone, but without requiring formal evidence of bone necrosis. ${ }^{111,116} \mathrm{ONJ}$ has been described in patients never exposed to bisphosphonates and regions of necrotic bone have been identified as a normal finding in the mandible of elderly individuals who have never received bisphosphonates. ${ }^{117}$ Osteonecrosis is a well-recognized phenomenon at other skeletal sites such as the hip and knee, but there is no evidence that osteonecrosis at either of these sites has any association with bisphosphonates. Interestingly, in these cases, therapy with bisphosphonates has even been reported to have beneficial outcomes in terms of preventing the progression of joint damage. ${ }^{118}$

Despite considerable effort, it has proved very difficult to produce lesions that might be relevant to human ONJ in animal models. None of the animal models to date fully simulate the human condition. ${ }^{119,120}$ The absence of appropriate animal models ${ }^{121}$ has also hampered efforts to search for plausible mechanisms.

Many pathogenic factors have been postulated to explain how bisphosphonates may play a role in ONJ. These include effects on blood supply, angiogenesis, excessive bone turnover in jaws leading to increased bisphosphonate uptake, excessive suppression by bisphosphonates of osteoclastic bone resorption, ${ }^{122}$ impaired mucosal healing, ${ }^{123}$ and use of other drugs (eg, immunosuppresives and glucocorticoids). Based on close scrutiny of the current evidence, none provide a plausible mechanism for how the use of bisphosphonates could lead to ONJ.

The premise that jawbones have an excessively high turnover relative to other parts of the skeleton, or that they selectively accumulate bisphosphonates, is in contrast to the work of Boyde and Kingsmill, ${ }^{117}$ whose findings suggest that turnover in the jawbones of elderly women is actually lower than many other skeletal sites, particularly trabecular bones. Also, in a study by Bauss et al, ${ }^{124}$ administration of ibandronate to male Wistar rats showed no evidence of preferential uptake in the jaw.

The suggestion that markers of bone resorption might be used to identify susceptible patients also does not stand up to close scrutiny. ${ }^{11,122,125-128}$

There are now reports from clinical trials of ONJ occurring in patients with advanced cancers in whom denosumab has been compared with zoledronate. The numbers of cases of ONJ were similar in both groups. There are no reports of ONJ when denosumab is given to patients with osteoporosis or with nondisseminated cancers, a finding which could be interpreted as meaning that ONJ may be associated with the advanced cancers per se rather than with the antiresorptive drugs.

Health care providers have been encouraged to advise their patients to practice good oral hygiene and have regular dental visits. If an invasive dental procedure is required, there is no evidence that discontinuation of bisphosphonate therapy improves dental outcomes, ${ }^{111}$ although many guidelines recommend some form of interruption. ${ }^{129}$

\section{Subtrochanteric or diaphyseal fractures}

A possible association between prolonged alendronate therapy and the occurrence of atypical subtrochanteric or diaphyseal fractures is a further example of adverse effects coming to attention as a result of publication of case reports and series. These fractures have been postulated to be the result of excessive reduction of bone remodeling. ${ }^{130-133}$ They often have a characteristic radiographic pattern, defined as a simple transverse fracture with a unicortical break in an area of cortical hypertrophy. Nevertheless, findings from a recent registry-based national cohort study from Denmark involving nearly 16,000 patients suggest that subtrochanteric fractures are likely to occur as a result of osteoporosis, and not as a complication of alendronate therapy. ${ }^{134}$ No reports have provided evidence of a possible link between the use of risedronate, ibandronate, or zoledronate and the occurrence of subtrochanteric fractures. In addition, a review of patients ( $n=3412$ ) who presented with clinical fractures over a period of 3 years revealed that subtrochanteric fractures represent less than $1 \%$ of all clinical fractures in patients older than 50 years, and that more than $90 \%$ of these fractures occurred in patients not taking bisphosphonates at the time of fracture. ${ }^{135}$ Mechanisms more plausible than "over-suppression" of bone turnover are, therefore, needed to explain the large majority of these fractures. Indeed, in a study of a patient on alendronate who eventually sustained bilateral fractures at the level of the femoral diaphysis, although bone formation was lower at the site of the fracture than in the iliac crest, the number of osteoclasts in the femoral cortex was 6-fold higher than in the iliac cancellous bone. ${ }^{136}$ Moreover, these osteoclasts had all the morphologic characteristics of normal active osteoclasts, and no resemblance to the giant osteoclasts described previously in patients treated with alendronate. ${ }^{137}$

Following a Europe-wide review of atypical stress fractures in bisphosphonates users, the Committee for Medicinal 
Products for Human Use (CHMP) introduced a new warning including information about these fractures into the Summary of Product Characteristics for alendronate. ${ }^{138}$ The CHMP further highlighted the uncertainty of a class effect for the other bisphosphonates and that unnecessary and inappropriate switching of bisphosphonates should be avoided. This concern has been reflected in the United Kingdom in recent safety advice from the Medicines and Healthcare products Regulatory Agency. ${ }^{139}$

\section{Effects of bisphosphonates on bone turnover}

Bisphosphonates exert their therapeutic effects by reducing bone resorption, and this leads to a reduction in bone remodeling and turnover. Since the effects of bisphosphonates on these processes can be very substantial, there has been a longstanding concern about whether there can be an "over-suppression" of bone turnover. The critical question is whether turnover can be reduced to an extent that impairs the repair of naturally occurring microdamage, thereby reducing the strength and mechanical quality of bone. ${ }^{140}$

Accumulation of bone microdamage has been reported in dogs after administration of alendronate at 5 times the clinical dose used for treatment of postmenopausal osteoporosis $^{141}$ and also in skeletally mature female beagles given alendronate or risedronate. ${ }^{142}$ There is some evidence for accumulation of microdamage in postmenopausal women treated with alendronate, ${ }^{143}$ but it is uncertain whether this leads to any change in mechanical properties. In contrast, microcrack frequency was found to be low when investigated in transiliac bone biopsies in 50 postmenopausal osteoporotic women treated with different nitrogen-containing bisphosphonates for at least 3 years. ${ }^{144}$

The degree of reduction of bone turnover achieved by each bisphosphonate, as well as the duration of action appears to be associated with their mineral-binding affinity and skeletal retention. Bisphosphonates with higher mineral-binding affinity and potential retention, such as alendronate and zoledronate, are associated with greater reduction of bone turnover and have a longer duration of effect after treatment is stopped. Bisphosphonates with lower mineral-binding affinity and retention, such as risedronate and etidronate, appear to reduce bone turnover less and this effect seems to be more readily reversible when therapy stops. ${ }^{7}$ In patients treated for 5 years with alendronate, bone turnover markers remained reduced, well below premenopausal levels for up to 5 years after discontinuation of treatment. ${ }^{52}$ Furthermore, following a single infusion of zoledronate, reduced bone turnover (close to the maximal achieved suppression) was sustained for at least 1 year. ${ }^{21}$ In patients treated for 3 years or 7 years ${ }^{57}$ with risedronate, bone turnover markers returned to pretreatment levels within 1 year after discontinuation of treatment. ${ }^{56}$

The effect of bisphosphonates on bone has also been assessed in several studies through histologic evaluation of bone biopsies, to determine both efficacy and safety. Such studies uniformly show that bisphosphonates reduce the "activation frequency" for the production of new remodeling units in bone. In patients treated with alendronate for up to 3 years, bone structure was maintained and no signs of impaired mineralization were observed. ${ }^{145}$ Similarly, histologic evaluations of bone biopsies from postmenopausal women receiving risedronate for up to 3 years showed preserved bone architecture and quality without evidence of osteomalacia, impaired bone mineralization, or other pathologic findings. ${ }^{18,146}$ Results from the BONE study also indicate that treatment with ibandronate for up to 3 years does not adversely affect bone quality and architecture, with histologic findings showing no signs of impaired mineralization, osteomalacia, marrow fibrosis, or cellular toxicity. ${ }^{147}$ Patients receiving an annual dosing of zoledronate for 3 years had a preserved trabecular bone structure and mineralization without evidence of adverse features. ${ }^{148}$

Finally, it should be noted that treatment with denosumab, a fully human monoclonal antibody that inhibits receptor activator of NF-kappa B ligand action, blocks the differentiation of osteoclasts and profoundly reduces bone resorption without, so far, any evidence of this being harmful. Denosumab appears to reduce turnover even more than bisphosphonates (alendronate was used as the comparator), though the effect of dramatic suppression of bone metabolic markers is rapidly reversible after only a few months. ${ }^{149}$ In the phase III clinical trials in osteoporosis, denosumab reduced fractures at all sites to an extent similar to that achieved with zoledronate. ${ }^{150,151}$

\section{For how long should bisphosphonates be given? The relevance of reversibility of effects}

Once bisphosphonate therapy is initiated, it is often asked whether treatment should be continued indefinitely, or whether "drug holidays" should be recommended, after 5 years or so. This debate raises the questions of whether prolonged reduction of bone turnover is ever harmful, and how rapidly the benefits of therapy for reducing fractures are lost when treatment stops. There is insufficient information to give unequivocal answers to these questions. However, it is important to tailor the treatment to the needs of the individual patient, and to remember that all bisphosphonates are not 
the same. As discussed early, when longer-acting bisphosphonates such as alendronate and zoledronate are used, the effects on reducing bone turnover are likely to persist for longer after stopping treatment than with the more reversible bisphosphonates such as risedronate and etidronate.

A recent review of the available evidence on long-term efficacy and safety of osteoporosis treatments indicated that it may be beneficial to continue osteoporosis therapy indefinitely in the majority of patients, with discontinuation of treatment likely to do more harm than if treatment is continued. ${ }^{152}$

\section{Interactions with PTH and implications for sequential therapy}

Treatment with parathyroid hormone (PTH) is currently the only therapeutic means of stimulating bone formation. In practice, many patients will have received bisphosphonates before this treatment, which may interfere with a subsequent "anabolic" response to PTH. Several studies suggest that the early treatment response to teriparatide (PTH 1-34) is attenuated by prior or concurrent treatment with alendronate. ${ }^{153-157}$ However, there are some reports that previous treatment with alendronate, risedronate, or nonbisphosphonate antiresorptive regimens does not affect the response to teriparatide. ${ }^{158,159}$ Nevertheless, bisphosphonates with a longer duration of action may interfere more with the response to PTH therapy than bisphosphonates with a more rapidly reversible effect. This is a possible explanation for the findings from a recent study, which evaluated the early anabolic effects of teriparatide in postmenopausal women with osteoporosis previously treated with alendronate or risedronate for at least 2 years. ${ }^{160}$ The results indicated that after 3 months of teriparatide treatment, patients who had received risedronate before had significantly greater increases in markers of bone formation than those who had previously received alendronate. The greater responsiveness to teriparatide in patients who had previously received risedronate rather than alendronate was also seen with changes in bone mass and some estimates of bone strength. ${ }^{161}$ This was still apparent after 1 year of treatment with teriparatide. ${ }^{160}$ It should be noted that regardless of prior treatment, the increase in bone formation induced by teriparatide was substantial, although the studies were not designed to test whether the beneficial effects on fractures was also maintained. There is emerging evidence that when PTH and zoledronate are given together there is no impairment of the response to PTH.

\section{Safety of nondaily oral bisphosphonate regimens}

A less frequent dosing regimen can offer the patient greater convenience in dosing and, therefore, possibly lead to greater compliance. There is now a substantial amount of information about the safety and efficacy of these alternate dosing regimens.

\section{Alendronate}

A 2-year active-control study of alendronate demonstrated that the tolerability profile and the proportions of patients discontinuing therapy due to adverse events were similar between daily $10 \mathrm{mg}$ and weekly $70 \mathrm{mg}$ treatment groups. Upper GI disorders occurred in $29.3 \%$ of patients receiving once-weekly alendronate and in $30 \%$ of patients receiving daily treatment. ${ }^{26}$ In a 3-month placebo-controlled clinical trial, once-weekly alendronate showed a tolerability profile comparable with placebo. ${ }^{162}$ A post hoc subgroup analysis of this trial indicated that the concomitant use of NSAIDs does not worsen the upper GI tolerability profile of once-weekly alendronate compared with placebo. ${ }^{163}$

\section{Risedronate}

In active-control studies, $5 \mathrm{mg}$ daily and $35 \mathrm{mg}$ weekly regimens of risedronate showed comparable safety profiles after both 1 and 2 years of treatment. ${ }^{29}$ In addition, the incidence and type of adverse events in general and GI side effects in particular were similar to what was reported for the daily regimen in placebo-controlled trials. ${ }^{18,19}$ Monthly regimens of risedronate (75 mg 2CDM and $150 \mathrm{mg}$ OaM) also showed a tolerability profile similar to that of daily regimen. The incidences of adverse events, adverse events leading to withdrawal, and upper GI tract adverse events were similar in both patient groups. ${ }^{30,31}$ Among the most common adverse events (abdominal pain, diarrhea, constipation, arthralgia, and influenza-like illness), only diarrhea and influenza-like illness had a substantially higher incidence in the OaM regimen compared with daily administration. ${ }^{31}$

\section{Ibandronate}

The active-control 2-year study of ibandronate, MOBILE, indicated that oral $2.5 \mathrm{mg}$ daily and $150 \mathrm{mg}$ OaM ibandronate regimens have similar safety profiles. ${ }^{36}$ The incidences of adverse events, drug-related adverse events, and drug-related adverse events leading to discontinuation were well balanced across both regimens. The incidence of upper GI tract side effects was also similar in both treatment groups. When only those who were taking aspirin and/or NSAIDs at baseline 
were considered, the upper GI tolerability profile of the 2 dosing regimens continued to be equivalent. Additional analyses from the MOTION study showed that GI tolerability with once-monthly $150 \mathrm{mg}$ ibandronate therapy was similar to that of weekly $70-\mathrm{mg}$ alendronate. ${ }^{47}$

\section{Conclusion}

As a drug class, bisphosphonates share many common properties; however, each has a unique pharmacologic profile that may help to explain potential clinical differences. It is well established that bisphosphonates can reduce the risk of fracture in men and women with osteoporosis and that they are generally viewed as well tolerated and safe, regardless of dosing regimen. When considering the various adverse events associated with bisphosphonates, it is important in each case to consider the strength of the evidence for a causal relationship, the benefit - risk profile of the chosen drug and the characteristics of the individual patient.

Although the issues of safety are of paramount importance, it is clear that some adverse events are receiving disproportionate attention given the scientifically inadequate data (eg, the risk for developing ONJ in patients treated with bisphosphonates for osteoporosis). It is important that these uncommon events do not deter clinicians from recognizing the value that appropriate use of these drugs can achieve in reducing fractures in many patients with osteoporosis. This is especially relevant when even today the majority of patients with fractures related to osteoporosis remain untreated.

\section{Disclosure}

In the early stages of preparation of this manuscript the authors received editorial/writing support funded by The Alliance for Better Bone Health (Procter \& Gamble Pharmaceuticals and sanofi-aventis U.S., Inc). However, the authors are fully responsible for all content and editorial decisions.

M Pazianas has received grant/research support from the Alliance for Better Bone Health. C Cooper has received honoraria and/or consulting fees from the Alliance for Better Bone Health, MSD, Eli Lilly, Novartis, GSK, Roche, Shire, Medtronic, and Amgen. F H Ebetino is an employee of Warner Chilcott Pharmaceuticals. R G G Russell has had consultant/advisory activities with Amgen, Glaxo-Smith-Kline, Eli Lilly, Novartis, Roche, Procter \& Gamble, Sanofi-Aventis, and Warner Chilcott Pharmaceuticals.

\section{References}

1. National Osteoporosis Foundation. Physician's Guide to Prevention and Treatment of Osteoporosis. Washington, DC: National Osteoporosis Foundation; 2003.
2. Eastell R. Pathogenesis of postmenopausal osteoporosis. In: Rosen CJ, Compston JE, Lian JB, editors. ASBMR Primer on the Metabolic Bone Diseases and Disorders of Mineral Metabolism. 7th ed. Washington, DC: American Society for Bone and Mineral Research; New York, NY: Wiley InterScience; 2008:259-262.

3. US Department of Health and Human Services. Bone Health and Osteoporosis: A Report of the Surgeon General. Rockville, MD: US Department of Health and Human Services, Office of the Surgeon General; 2004. Available from: http://surgeongeneral.gov/library/ bonehealth/index.html. Accessed Mar 24, 2010.

4. Harvey N, Dennison E, Cooper C. Osteoporosis: impact on health and economics. Nat Rev Rheumatol. 2010;6:99-105.

5. Burge R, Dawson-Hughes B, Solomon DH, Wong JB, King A, Tosteson A. Incidence and economic burden of osteoporosis-related fractures in the United States, 2005-2025. J Bone Miner Res. 2007;22: 465-475.

6. Epstein S. Update of current therapeutic options for the treatment of postmenopausal osteoporosis. Clin Ther. 2006;28:151-173.

7. Russell RGG, Watts NB, Ebetino FH, Rogers MJ. Mechanisms of action of bisphosphonates: similarities and differences and their potential influence on clinical efficacy. Osteoporos Int. 2008;19:733-759.

8. Nancollas GH, Tang R, Phipps RJ, et al. Novel insights into actions of bisphosphonates on bone: differences in interactions with hydroxyapatite. Bone. 2006;38:617-627.

9. Lawson MA, Xia Z, Barnett BL, et al. Differences between bisphosphonates in binding affinities for hydroxyapatite. J Biomed Mater Res B Appl Biomater. 2010;92(1):149-55.

10. Dunford JE, Thompson K, Coxon FP, et al. Structure-activity relationships for inhibition of farnesyl diphosphate synthase in vitro and inhibition of bone resorption in vivo by nitrogen-containing bisphosphonates. J Pharmacol Exp Ther. 2001;296:235-242.

11. Dunford JE, Kwaasi AA, Rogers MJ, et al. Structure-activity relationships among the nitrogen containing bisphosphonates in clinical use and other analogues: time-dependent inhibition of human farnesyl pyrophosphate synthase. J Med Chem. 2008;51(7):2187-2195.

12. Silverman SL, Watts NB, Delmas PD, Lange JL, Lindsay R. Effectiveness of bisphosphonates on nonvertebral and hip fractures in the first year of therapy: the risedronate and alendronate (REAL) cohort study. Osteoporos Int. 2007;18:25-34.

13. Recker RR, Lewiecki EM, Miller PD, Reiffel J. Safety of bisphosphonates in the treatment of osteoporosis. Am J Med. 2009;122 Suppl 2:S22-S32.

14. Watts NB, Diab DL. Long-term use of bisphosphosphonates [sic] in osteoporosis. J Clin Endocrinol Metab. 2010. Epub 2010 Feb 19. doi:10.1210/jc.2009-1947.

15. Black DM, Cummings SR, Karpf DB, et al. Randomised trial of effect of alendronate on risk of fracture in women with existing vertebral fractures. Fracture Intervention Trial Research Group. Lancet. 1996;348:1535-1541.

16. Cummings SR, Black DM, Thompson DE, et al. Effect of alendronate on risk of fracture in women with low bone density but without vertebral fractures: results from the Fracture Intervention Trial. JAMA. 1998;280:2077-2082.

17. Pols HA, Felsenberg D, Hanley DA, et al. Multinational, placebocontrolled, randomized trial of the effects of alendronate on bone density and fracture risk in postmenopausal women with low bone mass: results of the FOSIT study. Fosamax International Trial Study Group. Osteoporos Int. 1999;9:461-468.

18. Harris ST, Watts NB, Genant HK, et al. Effects of risedronate treatment on vertebral and nonvertebral fractures in women with postmenopausal osteoporosis: a randomized controlled trial. Vertebral Efficacy with Risedronate Therapy (VERT) Study Group. JAMA. 1999;282:1344-1352.

19. Reginster J, Minne HW, Sorensen OH, et al. Randomized trial of the effects of risedronate on vertebral fractures in women with established postmenopausal osteoporosis. Vertebral Efficacy with Risedronate Therapy (VERT) Study Group. Osteoporos Int. 2000;11:83-91. 
20. McClung MR, Geusens P, Miller PD, et al; for Hip Intervention Program Study Group. Effect of risedronate on the risk of hip fracture in elderly women. N Engl J Med. 2001;344:333-340.

21. Black DM, Delmas PD, Eastell R, et al; for HORIZON Pivotal Fracture Trial. Once-yearly zoledronic acid for treatment of postmenopausal osteoporosis. N Engl J Med. 2007;356:1809-1822.

22. Chesnut CH 3rd, Skag A, Christiansen C, et al. Effects of oral ibandronate administered daily or intermittently on fracture risk in postmenopausal osteoporosis. J Bone Miner Res. 2004;19:1241-1249.

23. Liberman UA, Weiss SR, Bröll J, et al. Effect of oral alendronate on bone mineral density and the incidence of fractures in postmenopausal osteoporosis. The Alendronate Phase III Osteoporosis Treatment Study Group. N Engl J Med. 1995;333(22):1437-1443.

24. Black DM, Thompson DE, Bauer DC, et al. Fracture risk reduction with alendronate in women with osteoporosis: the Fracture Intervention Trial. FIT Research Group. J Clin Endocrinol Metab. 2000;85:4118-4124. Erratum in: J Clin Endocrinol Metab. 2001;86(2):938.

25. Schnitzer T, Bone HG, Crepaldi G, et al. Therapeutic equivalence of alendronate $70 \mathrm{mg}$ once-weekly and alendronate $10 \mathrm{mg}$ daily in the treatment of osteoporosis. Alendronate Once-Weekly Study Group. Aging (Milano). 2000;12:1-12.

26. Rizzoli R, Greenspan SL, Bone G, et al. Two-year results of onceweekly administration of alendronate $70 \mathrm{mg}$ for the treatment of postmenopausal osteoporosis. J Bone Miner Res. 2002;17:1988-1996.

27. Roux C, Seeman E, Eastell R, et al. Efficacy of risedronate on clinical vertebral fractures within six months. Curr Med Res Opin. 2004;20:433-439.

28. Harrington JT, Ste-Marie LG, Brandi ML, et al. Risedronate rapidly reduces the risk for nonvertebral fractures in women with postmenopausal osteoporosis. Calcif Tissue Int. 2004;74:129-135.

29. Harris ST, Watts NB, Li Z, Chines AA, Hanley DA, Brown JP. Two-year efficacy and tolerability of risedronate once a week for the treatment of women with postmenopausal osteoporosis. Curr Med Res Opin. 2004;20:757-764. Erratum in: Curr Med Res Opin. 2004;20(10): 1690.

30. Delmas PD, Benhamou CL, Man Z, et al. Monthly dosing of $75 \mathrm{mg}$ risedronate on 2 consecutive days a month: efficacy and safety results. Osteoporos Int. 2008;19:1039-1045.

31. Delmas PD, McClung MR, Zanchetta JR, et al. Efficacy and safety of risedronate $150 \mathrm{mg}$ once a month in the treatment of postmenopausal osteoporosis. Bone. 2008;42:36-42.

32. Watts NB, Lindsay R, Li Z, Kasibhatla C, Brown J. Use of matched historical controls to evaluate the anti-fracture efficacy of once-a-week risedronate. Osteoporos Int. 2003;14:437-441.

33. Watts NB, Brown J, Cline G, Delmas PD. Two-consecutive days-a-month risedronate $75 \mathrm{mg}$ reduces vertebral fracture risk at one year. J Bone Miner Res. 2007;22 Suppl 1:W373.

34. Watts N, Klemes A, Wagner L, Brown J. Once-a-month risedronate $150 \mathrm{mg}$ reduced vertebral fracture risk at one year in a historical control analysis. J Bone Miner Res. 2008;23 Suppl 1:SU403.

35. Miller PD, McClung MR, Macovei L, et al. Monthly oral ibandronate therapy in postmenopausal osteoporosis: 1-year results from the MOBILE study. J Bone Miner Res. 2005;20:1315-1322.

36. Reginster JY, Adami S, Lakatos P, et al. Efficacy and tolerability of once-monthly oral ibandronate in postmenopausal osteoporosis: 2 year results from the MOBILE study. Ann Rheum Dis. 2006;65:654-661.

37. Delmas PD, Adami S, Strugala C, et al. Intravenous ibandronate injections in postmenopausal women with osteoporosis: one-year results from the dosing intravenous administration study. Arthritis Rheum. 2006;54:1838-1846.

38. Eisman JA, Civitelli R, Adami S, et al. Efficacy and tolerability of intravenous ibandronate injections in postmenopausal osteoporosis: 2-year results from the DIVA study. J Rheumatol. 2008;35: $488-497$.

39. Cranney A, Wells GA, Yetisir E, et al. Ibandronate for the prevention of nonvertebral fractures: a pooled analysis of individual patient data. Osteoporos Int. 2009;20:291-297.
40. Pazianas M, Epstein S, Zaidi M. Evaluating the antifracture efficacy of bisphosphonates. Rev Recent Clin Trials. 2009;4:122-130.

41. Lyles KW, Colon-Emeric CS, Magaziner JS, et al. Zoledronic acid and clinical fractures and mortality after hip fracture. $N$ Engl J Med. 2007;357:1799-1809.

42. Colón-Emeric CS, Mesenbrink P, Lyles KW, et al. Potential mediators of the mortality reduction with zoledronic acid after hip fracture. J Bone Miner Res. 2010;25:91-97.

43. Bolland MJ, Grey AB, Gamble GD, Reid IR. Effect of osteoporosis treatment on mortality: a meta-analysis. J Clin Endocrinol Metab. 2010;95(3):1174-1181.

44. Rosen CJ, Hochberg MC, Bonnick SL, et al; for Fosamax Actonel Comparison Trial Investigators. Treatment with once-weekly alendronate $70 \mathrm{mg}$ compared with once-weekly risedronate $35 \mathrm{mg}$ in women with postmenopausal osteoporosis: a randomized double-blind study. J Bone Miner Res. 2005;20:141-151.

45. Bonnick S, Saag KG, Kiel DP, et al. Comparison of weekly treatment of postmenopausal osteoporosis with alendronate versus risedronate over two years. J Clin Endocrinol Metab. 2006;91(7):2631-2637. Erratum in: J Clin Endocrinol Metab. 2007;92(8):3032.

46. Miller PD, Epstein S, Seddarati F, Reginster JY. Once-monthly oral ibandronate compared with weekly oral alendronate in postmenopausal osteoporosis: results from the head-to-head MOTION study. Curr Med Res Opin. 2008;24:207-213.

47. Emkey R, Delmas PD, Bolognese M, et al. Efficacy and tolerability of once-monthly oral ibandronate $(150 \mathrm{mg}$ ) and once-weekly oral alendronate $(70 \mathrm{mg})$ : additional results from the monthly oral therapy with ibandronate for osteoporosis intervention (MOTION) study. Clin Ther. 2009;31(4):751-761.

48. Watts NB, Cooper C, Lindsay R, et al. Relationship between changes in bone mineral density and vertebral fracture risk associated with risedronate: greater increases in bone mineral density do not relate to greater decreases in fracture risk. J Clin Densitom. 2004;7:255-261.

49. Delmas PD, Seeman E. Changes in bone mineral density explain little of the reduction in vertebral or nonvertebral fracture risk with antiresorptive therapy. Bone. 2004;34:599-604.

50. Eastell R, Barton I, Hannon RA, Chines A, Garnero P, Delmas PD. Relationship of early changes in bone resorption to the reduction in fracture risk with risedronate. J Bone Miner Res. 2003;18: 1051-1056.

51. Ensrud KE, Barrett-Connor EL, Schwartz A, et al. Randomized trial of effect of alendronate continuation versus discontinuation in women with low BMD: results from the Fracture Intervention Trial long-term extension. J Bone Miner Res. 2004;19:1259-1269.

52. Black DM, Schwartz AV, Ensrud KE, et al. Effects of continuing or stopping alendronate after 5 years of treatment: the Fracture Intervention Trial Long-term Extension (FLEX): a randomized trial. JAMA. 2006;296:2927-2938.

53. Sorensen OH, Crawford GM, Mulder H, et al. Long-term efficacy of risedronate: a 5-year placebo-controlled clinical experience. Bone. 2003;32:120-126.

54. Mellström DD, Sörensen OH, Goemaere S, Roux C, Johnson TD, Chines AA. Seven years of treatment with risedronate in women with postmenopausal osteoporosis. Calcif Tissue Int. 2004;75:462-468.

55. Devogelaer JP, Brown JP, Burckhardt P, et al. Zoledronic acid efficacy and safety over five years in postmenopausal osteoporosis. Osteoporos Int. 2007;18:1211-1218.

56. Watts NB, Chines A, Olszynski WP, et al. Fracture risk remain reduced one year after discontinuation of risedronate. Osteoporos Int. 2008;19:365-372.

57. Hannon R, Purple C, Klemes A, Cline G, Eastell R. Offset of effects on bone resorption after 7 years of risedronate therapy. ECTS (European Calcified Tissue Society) 2009: 36th European Symposium on Calcified Tissues; 2009 May 23-27; Vienna. Abstract OP08.

58. Grey A, Bolland MJ, Wattie D, Horne A, Gamble G, Reid IR. The antiresorptive effects of a single dose of zoledronate persist for two years: a randomized, placebo-controlled trial in osteopenic postmenopausal women. J Clin Endocrinol Metab. 2009;94(2):538-544. 
59. IMS Health. NPA Plus ${ }^{\mathrm{TM}}$ May 2006. Norwalk, CT: IMS Health Inc; 2006.

60. Green JR, Rogers M. Pharmacologic profile of zoledronic acid: a highly potent inhibitor of bone resorption. Drug Dev Res. 2002;55:210-224. doi:10.1002/ddr.10071.

61. Papapoulos SE, Cremers SC. Prolonged bisphosphonate release after treatment in children. $N$ Engl J Med. 2007;356(10):1075-1076.

62. Lufkin EG, Argueta R, Whitaker MD, et al. Pamidronate: an unrecognized problem in gastrointestinal tolerability. Osteoporos Int. 1994;4:320-322.

63. de Groen PC, Lubbe DF, Hirsch LJ, et al. Esophagitis associated with the use of alendronate. N Engl J Med. 1996;335(14):1016-1021.

64. Fosamax $^{\circledR}$ (alendronate sodium) prescribing information. Whitehouse Station, NJ: Merck and Co., Inc; Mar 2010. Available from: www. merck.com/product/usa/pi_circulars/f/fosamax/fosamax_pi.pdf. Accessed Mar 24, 2010.

65. Actonel ${ }^{\circledR}$ (risedronate sodium) prescribing information. Cincinnati, $\mathrm{OH}$ : Procter and Gamble Pharmaceuticals, Inc; Dec 2009. Available from: http://www.actonel.com/global/prescribing_information.pdf. Accessed Mar 24, 2010.

66. Boniva ${ }^{\circledR}$ (ibandronate sodium) prescribing information. South San Francisco, CA: Genentech USA Inc; Jan 2010. Available from: http:/ www.gene.com/gene/products/information/boniva/pdf/pi.pdf. Accessed Mar 24, 2010.

67. Lanza FL, Hunt RH, Thomson AB, Provenza JM, Blank MA. Endoscopic comparison of esophageal and gastroduodenal effects of risedronate and alendronate in postmenopausal women. Gastroenterology. 2000;119(3):631-638

68. Strampel W, Emkey R, Civitelli R. Safety considerations with bisphosphonates for the treatment of osteoporosis. Drug Saf. 2007;30:755-763.

69. Bauer DC, Black D, Ensrud K, et al. Upper gastrointestinal tract safety profile of alendronate: the Fracture Intervention Trial. Arch Intern Med. 2000;160:517-525.

70. Taggart H, Bolognese MA, Lindsay R, et al. Upper gastrointestinal tract safety of risedronate: a pooled analysis of 9 clinical trials. Mayo Clin Proc. 2002;77:262-270. Erratum in: Mayo Clin Proc. 2002;77(6):601.

71. Boniva ${ }^{\circledR}$ (ibandronate sodium) injection prescribing information. South San Francisco, CA: Genentech USA Inc; Mar 2010. Available from: http://www.gene.com/gene/products/information/boniva/pdf/ Injection_pi.pdf. Accessed Mar 24, 2010.

72. Reclast ${ }^{\mathbb{1}}$ (zoledronic acid) prescribing information. Stein, Switzerland: Novartis Pharma Stein AG; May 2009. Available from: http://www. pharma.us.novartis.com/product/pi/pdf/reclast.pdf. Accessed Mar 24, 2010.

73. Epstein S, Geusens P, Fisher JE, et al. Disintegration and esophageal irritation profiles of alendronate formulations: implications for clinical safety and efficacy. J Appl Res. 2005;5(2):253-265. Available from: http://www.jarcet.com/articles/Vol5Iss2/index.htm.

74. Epstein S, Cryer B, Ragi S, et al. Disintegration/dissolution profiles of copies of Fosamax (alendronate). Curr Med Res Opin. 2003;19:781-789. Erratum in: Curr Med Res Opin. 2004;20(4):575.

75. Dansereau RJ, Crail DJ, Perkins AC. In vitro disintegration and dissolution studies of once-weekly copies of alendronate sodium tablets $(70 \mathrm{mg})$ and in vivo implications. Curr Med Res Opin. 2008;24:1137-1145.

76. Dansereau RJ, Crail DJ, Perkins AC. In vitro disintegration studies of weekly generic alendronate sodium tablets $(70 \mathrm{mg})$ available in the US. Curr Med Res Opin. 2009;25:449-452.

77. Grima DT, Papaioannou A, Thompson MF, Pasquale MK, Adachi JD. Greater first year effectiveness drives favorable cost-effectiveness of brand risedronate versus generic or brand alendronate: modeled Canadian analysis. Osteoporos Int. 2008;19(5):687-697.

78. Ringe JD, Möller G. Differences in persistence, safety and efficacy of generic and original branded once weekly bisphosphonates in patients with postmenopausal osteoporosis: 1-year results of a retrospective patient chart review analysis. Rheumatol Int. 2009;30: 213-221.
79. Miller PD, Roux C, Boonen S, Barton IP, Dunlap LE, Burgio DE. Safety and efficacy of risedronate in patients with age-related reduced renal function as estimated by the Cockcroft and Gault method: a pooled analysis of nine clinical trials. J Bone Miner Res. 2005;20:2105-2115.

80. Miller PD, Miday R, Klemes A, Ramsey D. Renal safety across a wide range of dosing regimens of risedronate. $J$ Bone Miner Res. 2008;23 Suppl 1:SA402.

81. Jamal SA, Bauer DC, Ensrud KE, et al. Alendronate treatment in women with normal to severely impaired renal function: an analysis of the Fracture Intervention Trial. J Bone Miner Res. 2007;22:503-508.

82. Perazella MA, Markowitz GS. Bisphosphonate nephrotoxicity. Kidney Int. 2008;74(11):1385-1393.

83. Adami S, Bhalla AK, Dorizzi R, et al. The acute-phase response after bisphosphonate administration. Calcif Tissue Int. 1987;41(6):326-331.

84. Frijlink WB, Bijvoet OL, te Velde J, Heynen G. Treatment of Paget's disease with (3-amino-1-hydroxypropylidene)-1, 1-bisphosphonate (A.P.D.) Lancet. 1979;1(8120):799-803.

85. Thompson K, Rogers MJ. Statins prevent bisphosphonate-induced $\gamma, \delta$-T-cell proliferation and activation in vitro. $J$ Bone Miner Res. 2004;19:278-288.

86. Coxon FP, Thompson K, Rogers MJ. Recent advances in understanding the mechanism of action of bisphosphonates. Curr Opin Pharmacol. 2006;6(3):307-312.

87. Hewitt RE, Lissina A, Green AE, Slay ES, Price DA, Sewell AK. The bisphosphonate acute phase response: rapid and copious production of proinflammatory cytokines by peripheral blood gd $\mathrm{T}$ cells in response to aminobisphosphonates is inhibited by statins. Clin Exp Immunol. 2005;139(1):101-111.

88. Roelofs AJ, Jauhiainen M, Mönkkönen H, Rogers MJ, Mönkkönen J, Thompson K. Peripheral blood monocytes are responsible for gammadelta $\mathrm{T}$ cell activation induced by zoledronic acid through accumulation of IPP/DMAPP. Br J Haematol. 2009;144(2):245-250.

89. US Food and Drug Administration (FDA). Severe Pain with Osteoporosis Drugs. Silver Spring, MD: FDA; 2008. Available from: http://www. accessdata.fda.gov/scripts/cdrh/cfdocs/psn/transcript.cfm?show=79\#2. Accessed Mar 24, 2010.

90. Pazianas M, Compston J, Huang CL. Atrial fibrillation and bisphosphonate therapy. J Bone Miner Res. 2010;25(1):2-10.

91. Cummings SR, Schwartz AV, Black DM. Alendronate and atrial fibrillation. $N$ Engl J Med. 2007;356:1895-1896.

92. Karam R, Camm J, McClung M. Yearly zoledronic acid in postmenopausal osteoporosis. N Engl J Med. 2007;357:712-713.

93. Lewiecki EM, Cooper C, Thompson E, Hartl F, Mehta D, Papapoulos SE. Ibandronate does not increase risk of atrial fibrillation in analysis of pivotal clinical trials. Int J Clin Pract. In press 2010.

94. Heckbert SR, Li G, Cummings SR, Smith NL, Psaty BM. Use of alendronate and risk of incident atrial fibrillation in women. Arch Intern Med. 2008;168:826-831.

95. Sørensen HT, Christensen S, Mehnert F, et al. Use of bisphosphonates among women and risk of atrial fibrillation and flutter: population based case-control study. BMJ. 2008;336:813-816.

96. Abrahamsen B, Eiken P, Brixen K. Atrial fibrillation in fracture patients treated with oral bisphosphonates. J Intern Med. 2009;265(5):581-592.

97. Grosso A, Douglas I, Hingorani A, MacAllister R, Smeeth L. Oral bisphosphonates and risk of atrial fibrillation and flutter in women: a selfcontrolled case-series safety analysis. PLoS ONE. 2009;4(3):e4720.

98. Loke YK, Jeevanantham V, Singh S. Bisphosphonates and atrial fibrillation: systematic review and meta-analysis. Drug Saf. 2009;32:219-228.

99. US Food and Drug Administration (FDA). Update of Safety Review Follow-up to the Oct 1, 2007 Early Communication about the Ongoing Safety Review of Bisphosphonates. Silver Spring, MD: FDA; 2008. Available from: http://www.fda.gov/Drugs/DrugSafety/Post marketDrugSafetyInformationforPatientsandProviders/DrugSafety InformationforHeathcareProfessionals/ucm136201.htm. Accessed Mar 24, 2010. 
100. Medicines and Healthcare products Regulatory Agency (MHRA). Bisphosphonates: atrial fibrillation. Drug Safety Update. 2008;1(12):4. London, UK: MHRA. Available from: http://www.mhra.gov.uk/ Publications/Safetyguidance/DrugSafetyUpdate/CON020566. Accessed Mar 24, 2010.

101. European Medicines Agency (EMEA). Aclasta (zoledronic acid): European Public Assessment Report, revision 9. London: EMEA; Jul 8, 2009. Available from: http://www.emea.europa.eu/ humandocs/Humans/EPAR/aclasta/aclasta.htm. Accessed Mar 24, 2010.

102. Malik AR, Campbell SH, Toma NM. Bilateral acute anterior uveitis after alendronate. Br J Ophthalmol. 2002;86:1443.

103. Fraunfelder FW, Fraunfelder FT. Bisphosphonates and ocular inflammation. N Engl J Med. 2003;348:1187-1188.

104. Benderson D, Karakunnel J, Kathuria S, Badros A. Scleritis complicating zoledronic acid infusion. Clin Lymphoma Myeloma. 2006;7:145-147.

105. Moore MM, Beith JM. Acute unilateral anterior uveitis and scleritis following a single infusion of zoledronate for metastatic breast cancer. Med J Aust. 2008;188:370-371.

106. Banal F, Briot K, Ayoub G, Dougados M, Roux C. Unilateral anterior uveitis complicating zoledronic acid therapy in prostate cancer. $J$ Rheumatol. 2008;35(12):2458-2459.

107. Sharma NS, Ooi JL, Masselos K, Hooper MJ, Francis IC. Zoledronic acid infusion and orbital inflammatory disease. $N$ Engl $J$ Med. 2008;359(13):1410-1411.

108. Wysowski DK. Reports of esophageal cancer with oral bisphosphonate use. $N$ Engl J Med. 2009;360:89-90.

109. Newcomb PA, Trentham-Dietz A, Hampton JM. Bisphosphonates for osteoporosis treatment are associated with reduced breast cancer risk. Br J Cancer. 2010;102(5):799-802.

110. Cooper C, Steinbuch M, Stevenson R, Miday R, Watts NB. The epidemiology of osteonecrosis: findings from the GPRD and THIN databases in the UK. Osteoporos Int. 2010;21(4):569-577.

111. Khosla S, Burr D, Cauley J, et al. Bisphosphonate-associated osteonecrosis of the jaw: report of a task force of the American Society for Bone and Mineral Research. J Bone Miner Res. 2007;22:1479-1491.

112. Pazianas M, Miller P, Blumentals WA, Bernal M, Kothawala P. A review of the literature on osteonecrosis of the jaw in patients with osteoporosis treated with oral bisphosphonates: prevalence, risk factors, and clinical characteristics. Clin Ther. 2007;8: $1548-1558$.

113. Khan AA, Sandor GK, Dore E, et al. Bisphosphonate associated osteonecrosis of the jaw. Canadian Task Force on Osteonecrosis of the Jaw. J Rheumatol. 2009;36(3):478-490.

114. Woo SB, Hellstein JW, Kalmar JR. Systematic review: bisphosphonates and osteonecrosis of the jaws. Ann Intern Med. 2006;144:753-761.

115. Wimalawansa SJ. Insight into bisphosphonate-associated osteomyelitis of the jaw: pathophysiology, mechanisms and clinical management. Expert Opin Drug Saf. 2008;7(4):491-512.

116. American Association of Oral and Maxillofacial Surgeons position paper on bisphosphonate-related osteonecrosis of the jaws. Advisory Task Force on Bisphosphonate-Related Ostenonecrosis of the Jaws, American Association of Oral and Maxillofacial Surgeons. J Oral Maxillofac Surg. 2007;65:369-376.

117. Boyde A, Kingsmill VJ. Age changes in bone. Gerodontology. 1998;15:25-34.

118. Agarwala S, Shah S, Joshi VR. The use of alendronate in the treatment of avascular necrosis of the femoral head: follow-up to eight years. J Bone Joint Surg Br. 2009;91(8):1013-1018.

119. Allen MR, Burr DB. Mandible matrix necrosis in beagle dogs after 3 years of daily oral bisphosphonate treatment. J Oral Maxillofac Surg. 2008;66:987-994.

120. Sonis ST, Watkins BA, Lyng GD, Lerman MA, Anderson KC. Bony changes in the jaws of rats treated with zoledronic acid and dexamethasone before dental extractions mimic bisphosphonate-related osteonecrosis in cancer patients. Oral Oncol. 2009;45:164-172.
121. Allen MR. Animal models of osteonecrosis of the jaw. J Musculoskelet Neuronal Interact. 2007;7:358-360.

122. Novince CM, Ward BB, McCauley LK. Osteonecrosis of the jaw: an update and review of recommendations. Cells Tissues Organs. 2009; 189:275-283.

123. Reid IR. Osteonecrosis of the jaw - Who gets it, and why? Bone. 2009;44:4-10.

124. Bauss F, Pfister T, Papapoulos S. Ibandronate uptake in the jaw is similar to long bones and vertebrae in the rat. $J$ Bone Miner Metab. 2008;26(4):406-408.

125. Silverman SL, Landesberg R. Osteonecrosis of the jaw and the role of bisphosphonates: a critical review. Am J Med. 2009;122 Suppl 2:S33-S45.

126. Lehrer S, Montazem A, Ramanathan L, et al. Normal serum bone markers in bisphosphonate-induced osteonecrosis of the jaws. Oral Surg Oral Med Oral Pathol Oral Radiol Endod. 2008;106:389-391.

127. Lehrer S, Montazem A, Ramanathan L, et al. Bisphosphonate-induced osteonecrosis of the jaws, bone markers, and a hypothesized candidate gene. J Oral Maxillofac Surg. 2009;67:159-161.

128. Grbic JT, Landesberg R, Lin SQ, et al; for Health Outcomes and Reduced Incidence with Zoledronic Acid Once Yearly Pivotal Fracture Trial Research Group. Incidence of osteonecrosis of the jaw in women with postmenopausal osteoporosis in the health outcomes and reduced incidence with zoledronic acid once yearly pivotal fracture trial. $\mathrm{JAm}$ Dent Assoc. 2008;139(1):32-40.

129. American Dental Association "Expert panel recommendations for the prevention, diagnosis, and treatment of osteonecrosis of the jaws: June 2004." Available from: http://www.ada.org/sections/professional Resources/pdfs/topics_osteonecrosis_whitepaper.pdf. Accessed Apr 8, 2010.

130. Goh SK, Yang KY, Koh JS, et al. Subtrochanteric insufficiency fractures in patients on alendronate therapy: a caution. J Bone Joint Surg Br. 2007;89:349-353.

131. Lenart BA, Lorich DG, Lane JM. Atypical fractures of the femoral diaphysis in postmenopausal women taking alendronate. $N$ Engl $J$ Med. 2008;358:1304-1306.

132. Kwek EBK, Goh SK, Koh JSB, Png MA, Howe TS. An emerging pattern of subtrochanteric stress fractures: a long-term complication of alendronate therapy? Injury. 2008;39:224-231.

133. Neviaser AS, Lane JM, Lenart BA, Edobor-Osula F, Lorich DG. Low-energy femoral shaft fractures associated with alendronate use. J Orthop Trauma. 2008;22:346-350.

134. Abrahamsen B, Eiken P, Eastell R. Subtrochanteric and diaphyseal femur fractures in patients treated with alendronate: a register-based national cohort study. J Bone Miner Res. 2009;24(6): 1095-1102.

135. Boonen A, Wakefield D, Huntjens K, van Helden S, Geusens P. The prevalence of subtrochanteric fractures in patients older than 50 years presenting with a clinical vertebral or non-vertebral fracture. $J$ Bone Miner Res. 2008;23 Suppl 1. Abstract Su390.

136. Somford MP, Draijer FW, Thomassen BJ, Chavassieux PM, Boivin G, Papapoulos SE. Bilateral fractures of the femur diaphysis in a patient with rheumatoid arthritis on long-term treatment with alendronate: clues to the mechanism of increased bone fragility. J Bone Miner Res. 2009;24(10):1736-1740.

137. Weinstein RS, Roberson PK, Manolagas SC. Giant osteoclast formation and long-term oral bisphosphonate therapy. $N$ Engl J Med. 2009;360(1):53-62.

138. European Medicines Agency (EMEA). Committee for Medicinal Products for Human Use February 2009 Plenary Meeting Monthly Report. London: EMEA; Feb 26, 2009. Available from: http://www.emea.europa. eu/pdfs/human/press/pr/9779509en.pdf. Accessed Mar 24, 2010.

139. Medicines and Healthcare products Regulatory Agency (MHRA). Bisphosphonates: atypical stress fractures. Drug Safety Update. 2009;2(8):8. London, UK: MHRA. Available from: http://www.mhra. gov.uk/Publications/Safetyguidance/DrugSafetyUpdate/CON041211. Accessed Mar 24, 2010. 
140. Mashiba T, Hirano T, Turner CH, Forwood MR, Johnston CC, Burr DB. Suppressed bone turnover by bisphosphonates increases microdamage accumulation and reduces some biomechanical properties in dog rib. J Bone Miner Res. 2000;15:613-620.

141. Mashiba T, Turner CH, Hirano T, Forwood MR, Johnston CC, Burr DB Effects of suppressed bone turnover by bisphosphonates on microdamage accumulation and biomechanical properties in clinically relevant skeletal sites in beagles. Bone. 2001;28:524-531.

142. Allen MR, Iwata K, Phipps R, Burr DB. Alterations in canine vertebral bone turnover, microdamage accumulation, and biomechanical properties following 1-year treatment with clinical treatment doses of risedronate or alendronate. Bone. 2006;39:872-879.

143. Stepan JJ, Burr DB, Pavo I, et al. Low bone mineral density is associated with bone microdamage accumulation in postmenopausal women with osteoporosis. Bone. 2007;41:3378-3385.

144. Chapurlat RD, Arlot M, Burt-Pichat B, et al. Microcrack frequency and bone remodeling in postmenopausal osteoporotic women on long-term bisphosphonates: a bone biopsy study. $J$ Bone Miner Res. 2007;22:1502-1509.

145. Chavassieux PM, Arlot ME, Reda C, Wei L, Yates AJ, Meunier PJ. Histomorphometric assessment of the long-term effects of alendronate on bone quality and remodeling in patients with osteoporosis. J Clin Invest. 1997;100:1475-1480.

146. Eriksen EF, Melsen F, Sod E, Barton I, Chines A. Effects of longterm risedronate on bone quality and bone turnover in women with postmenopausal osteoporosis. Bone. 2002;31:620-625.

147. Recker RR, Weinstein RS, Chesnut III CH, et al. Histomorphometric evaluation of daily and intermittent oral ibandronate in women with postmenopausal osteoporosis: results from the BONE study. Osteoporos Int. 2004;15:231-237.

148. Recker RR, Delmas PD, Halse J, et al. Effects of intravenous zoledronic acid once yearly on bone remodeling and bone structure. J Bone Miner Res. 2008;23:6-16.

149. Brown JP, Prince RL, Deal C, et al. Comparison of the effect of denosumab and alendronate on BMD and biochemical markers of bone turnover in postmenopausal women with low bone mass: a randomized, blinded, phase 3 trial. J Bone Miner Res. 2009;24(1):153-161.

150. Cummings SR, San Martin J, McClung MR, et al, for the FREEDOM Trial. Denosumab for prevention of fractures in postmenopausal women with osteoporosis. N Engl J Med. 2009;361(8):756-765.

151. Khosla S. Increasing options for the treatment of osteoporosis. $\mathrm{NEngl}$ J Med. 2009;361(8):818-820.

152. Seeman E. To stop or not to stop, that is the question. Osteoporos Int. 2009;20(2):187-195.
153. Ettinger B, San Martin J, Crans G, Pavo I. Differential effects of teriparatide on BMD after treatment with raloxifene or alendronate. J Bone Miner Res. 2004;19(5):745-751.

154. Black DM, Greenspan SL, Ensrud KE, et al. The effects of parathyroid hormone and alendronate alone or in combination in postmenopausal osteoporosis. N Engl J Med. 2003;349:1207-1215.

155. Finkelstein JS, Hayes A, Hunzelman JL, Wyland JJ, Lee H, Neer RM. The effects of parathyroid hormone, alendronate, or both in men with osteoporosis. N Engl J Med. 2003;349:1216-1226.

156. Finkelstein JS, Leder BZ, Burnett SA, et al. Effects of teriparatide, alendronate, or both on bone turnover in osteoporotic men. J Clin Endocrinol Metab. 2006;91:2882-2887.

157. Obermayer-Pietsch BM, Marin F, McCloskey EV, et al; for EUROFORS Investigators. Effects of two years of daily teriparatide treatment on BMD in postmenopausal women with severe osteoporosis with and without prior antiresorptive treatment. J Bone Miner Res. 2008;23(10):1591-1600.

158. Boonen S, Marin F, Obermayer-Pietsch B, et al; for EUROFORS Investigators. Effects of previous antiresorptive therapy on the bone mineral density response to two years of teriparatide treatment in postmenopausal women with osteoporosis. J Clin Endocrinol Metab. 2008;93:852-860.

159. Eastell R, Nickelsen T, Marin F, et al. Sequential treatment of severe postmenopausal osteoporosis after teriparatide: final results of the randomized, controlled European Study of Forsteo (EUROFORS). J Bone Miner Res. 2009;24(4):726-736.

160. Miller PD, Delmas PD, Lindsay R, et al. Early responsiveness of women with osteoporosis to teriparatide after therapy with alendronate or risedronate. J Clin Endocrinol Metab. 2008;93: 3785-3793.

161. Chevalier Y, Quek E, Borah B, et al. Biomechanical effects of teriparatide in women with osteoporosis treated previously with alendronate and risedronate: results from quantitative computed tomography-based finite element analysis of the vertebral body. Bone. 2010;46(1):41-48.

162. Greenspan S, Field-Munves E, Tonino R, et al. Tolerability of once-weekly alendronate in patients with osteoporosis: a randomized, double-blind, placebo-controlled study. Mayo Clin Proc. 2002;77:1044-1052.

163. Cryer B, Miller P, Petruschke RA, Chen E, Geba GP, Papp AE. Upper gastrointestinal tolerability of once weekly alendronate $70 \mathrm{mg}$ with concomitant non-steroidal anti-inflammatory drug use. Aliment Pharmacol Ther. 2005;21:599-607.
Therapeutics and Clinical Risk Management

\section{Publish your work in this journal}

Therapeutics and Clinical Risk Management is an international, peerreviewed journal of clinical therapeutics and risk management, focusing on concise rapid reporting of clinical studies in all therapeutic areas, outcomes, safety, and programs for the effective, safe, and sustained use of medicines. This journal is indexed on PubMed Central, CAS,

\section{Dovepress}

EMBase, Scopus and the Elsevier Bibliographic databases. The manuscript management system is completely online and includes a very quick and fair peer-review system, which is all easy to use. Visit http://www.dovepress.com/testimonials.php to read real quotes from published authors. 